University of Louisville

ThinkIR: The University of Louisville's Institutional Repository

Electronic Theses and Dissertations

$12-2004$

\title{
Electrical charge distribution studies in SWNT, C60@SWNT, and DWNT structures.
}

Jose E. Rivera 1961-

University of Louisville

Follow this and additional works at: https://ir.library.louisville.edu/etd

\section{Recommended Citation}

Rivera, Jose E. 1961-, "Electrical charge distribution studies in SWNT, C60@SWNT, and DWNT structures." (2004). Electronic Theses and Dissertations. Paper 1212.

https://doi.org/10.18297/etd/1212

This Master's Thesis is brought to you for free and open access by ThinkIR: The University of Louisville's Institutional Repository. It has been accepted for inclusion in Electronic Theses and Dissertations by an authorized administrator of ThinkIR: The University of Louisville's Institutional Repository. This title appears here courtesy of the author, who has retained all other copyrights. For more information, please contact thinkir@louisville.edu. 


\title{
ELECTRICAL CHARGE DISTRIBUTION STUDIES IN SWNT, C60@SWNT, AND DWNT STRUCTURES
}

\author{
By \\ Jose E. Rivera \\ B.S., University of Louisville, 2002

\begin{abstract}
A Thesis
Submitted to the Faculty of the Graduate School of the University of Louisville in Partial Fulfillment of the Requirements for the Degree of
\end{abstract} \\ Master of Science \\ Department of Physics \\ University of Louisville \\ Louisville, Kentucky
}

December 2004 


\title{
ELECTRICAL CHARGE DISTRIBUTION STUDIES IN SWNT, C60@SWNT, AND DWNT STRUCTURES
}

\author{
By
}

Jose E. Rivera

B.S., University of Louisville, 2002

A Thesis approved on

December 2004

By the following Reading Committee:

Dr. Gamini Sumanasekera, Thesis Director

Dr. Shi Yu Wu

Dr. Bruce Alphenaar 


\section{ACKNOWLEDGEMENTS}

I acknowledge with pleasure and gratitude to all the people in the Physics department, machine shop, electronic shop, and the Physics nano-lab who assisted me and gave me moral support while editing this thesis: This work has been greatly enriched by the efforts of Dr. Gamini Sumanasekera who has contributed to my education.

I want to thank my parents for their continued love. This thesis as one means to thank my ex-family-inlaw who extended their unfaltering kindness and goodwill to me. I want to express my gratitude to my ex-wife Lee Ann, to whom I dedicate this thesis. 


\title{
ABSTRACT \\ ELECTRICAL CHARGE DISTRIBUTION STUDIES IN SWNT, C60@SWNT, AND STRUCTURES
}

\author{
José E. Rivera
}

December 2004

Single Walled Carbon Nanotubes (SWNTs), Double Walled Carbon nanotubes (DWNTs) and C60@SWNT (peapods) are three of well-ordered all-carbon nanostructures. Peapods are SWNTs filled with $\mathrm{C}_{60}$ fullerene peas. At high temperatures, $\mathrm{C}_{60}$ molecules coalesce into a long internal SWNT forming a DWNT. Charge transfer properties on SWNTs (both donor and acceptor type) have been studied intensively by various groups. Few groups have conducted such studies on peapods and DWNTs. In a recent study on $\mathrm{Br} 2$ doping of DWNTs using Raman spectroscopy, it has been found that the net charge primarily resides on the outer tube revealing molecular Faraday cage effect even when the outer layer is semiconducting and inner layer is metallic. We are investigating charge distribution behavior in these structures by a systematic electrical transport study (both resistivity and Seebeck coefficient) by way of doping with potassium (donor). 


\section{TABLE OF CONTENTS}

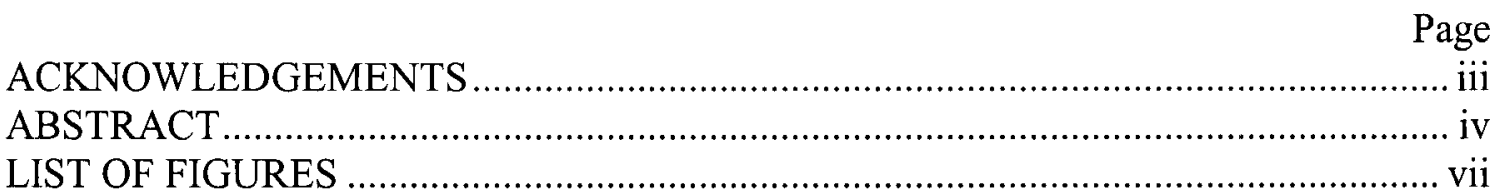

\section{CHAPTER}

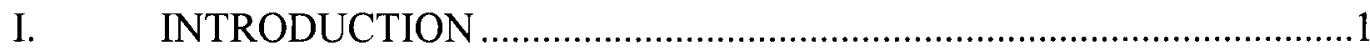

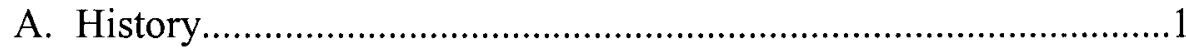
B. Fullerene-60

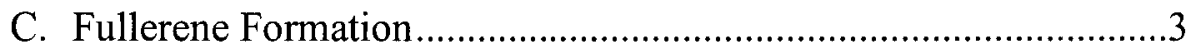
D. Fullerene Electronic Structure …....................................................

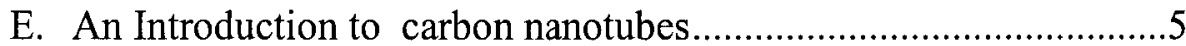
F. Double-Walled Carbon Nanotubes ..............................................11
G. Synthesis of Double Wall Nanotubes ...........................................13

H. Synthesis of Double Wall Nanotubes in the Physics laboratory....14

I. Raman Spectroscopic study on charge transfer .............................16

J. Synthesis of carbon nanotubes....................................................

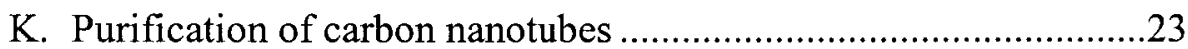

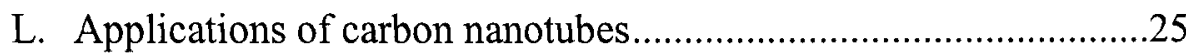


II. MEASUREMENT SYSTEM: THE THERMOPOWER AND DC FOUR-PROBE ELECTRICAL RESISTANCE.

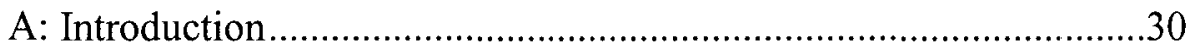

B: An Introduction to Seebeck Coefficient (Thermopowe).......... 31

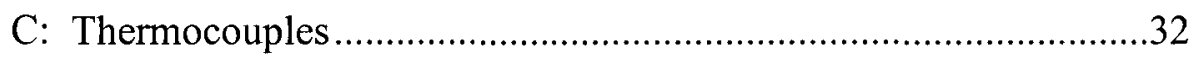

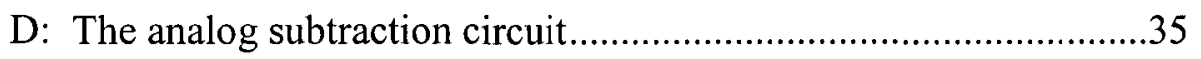

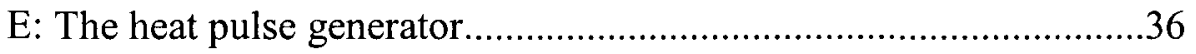

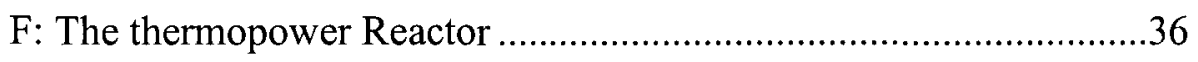

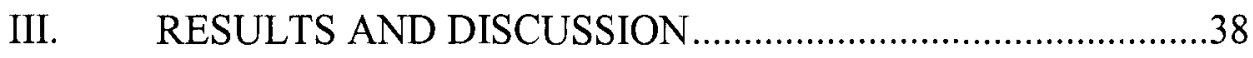

CONCLUSION

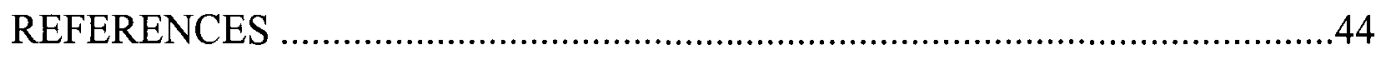

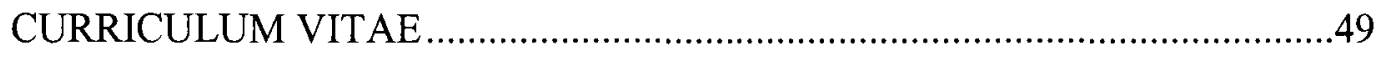




\section{LIST OF FIGURES}

FIGURE

PAGE

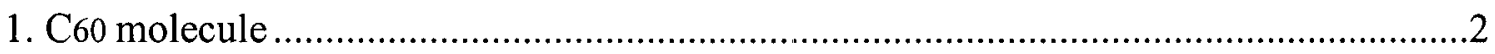

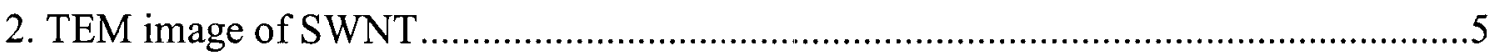

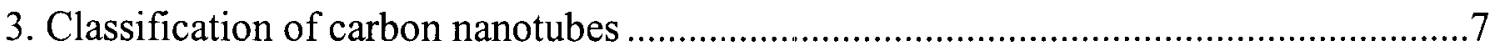

4. The unrolled honeycomb lattice of a nanotube .........................................................

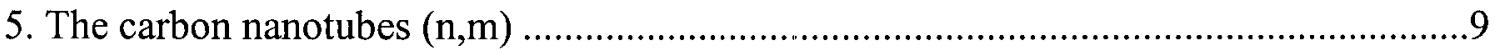

6. Density of states of semi-conducting and metallic tube ............................................10

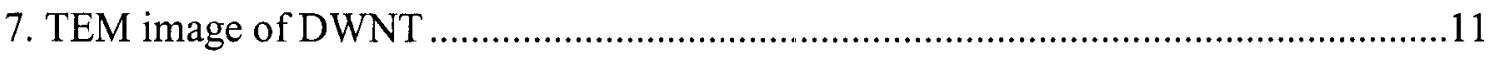

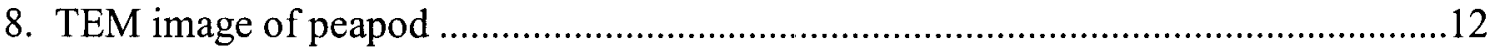

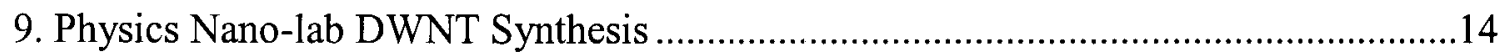

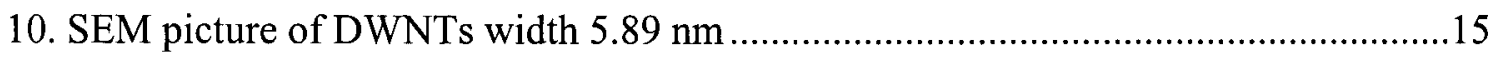

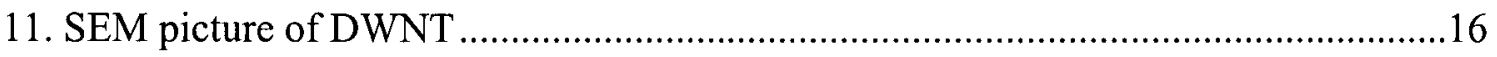

12. Raman scattering spectra of DWNTs using $1064 \mathrm{~nm}$ laser excitation ........................18

13. Raman scattering spectra of DWNT and SWNT tangential mode ..............................18

14. Tube diameter dependence of the energy separation................................................19

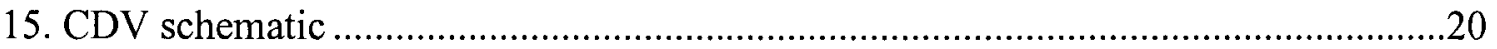

16. Schematic of pulse laser vaporization system …....................................................22

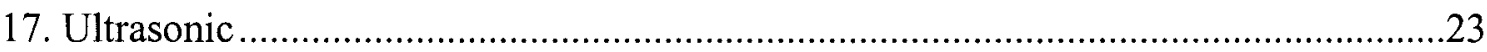

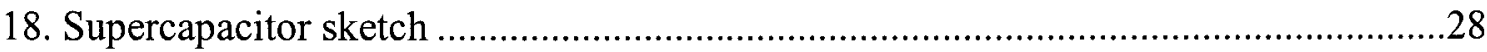


19. Five potential devises based on nanotubes

20. Thermocouples assembler $\mathrm{G}$

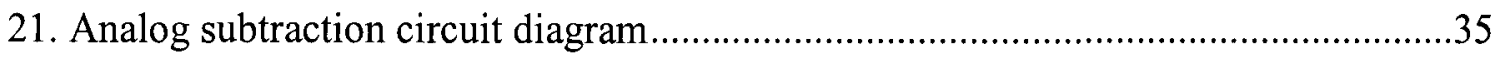

22. Block diagram of thermopower measurement system ................................................35

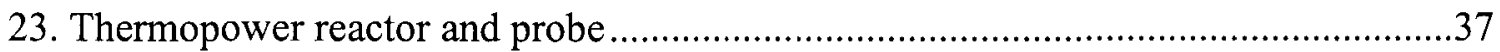

24. Reactor containing potassium ampoule and sample ...............................................37

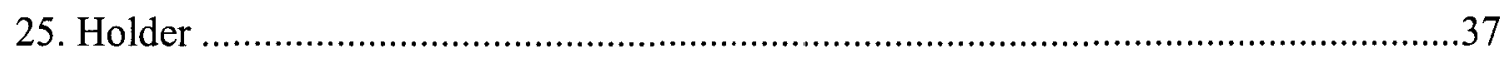

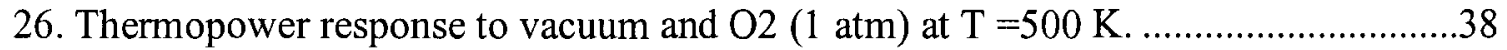

27. A typical in situ variation of four-probe dc resistance R of K-doped SWNT mats normalize to the $\mathrm{T}=400 \mathrm{~K}$ resitance of the pristine SWNT mat as a function of

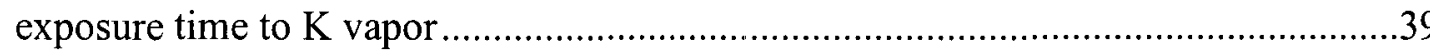

28. In situ variation of four-probe resistance R of K-doped SWNT, peapods and DWNT matss normalized to the $\mathrm{T}=412 \mathrm{~K}$ .40

29. In situ variation Thermopower S of K-doped SWNT, peapods, and DWNT mats as a function of exposure time to $\mathrm{K}$ vapor. 41

30. Temperature dependence of (a) Resistance R (b) TEP S before and after saturation doping with K for SWNTs peapods, and DWNT mats. 


\section{CHAPTER I \\ INTRODUCTION}

A. History

Carbon fibers can be thought as the macroscopic analog of carbon nanotubes. The early history of carbon fibers was stimulated by needs for materials with special properties, both in the $19^{\text {th }}$ century and more recently after World War II. Thomas A. Edison prepared the first carbon fiber for a filament to be used in the early model of an electric light bulb. In the 1950's and 60's carbon fiber and carbon whisker research increased by the needs of the space and aircraft industry for strong, stiff, light-weight fibers that could be used for building light weight composite materials with superior mechanical properties. The desire to synthesize more crystalline filamentous carbons under more controlled conditions, synthesis of carbon fibers by a catalytic chemical vapor deposition (CVD) process proceeded in the 1960's and early 1970's. [28]

In 1970 the $\mathrm{C}_{60}$ molecule first appeared in the literature in an article by Osawa C. Kagaku [8]. Osawa and Yoshida described it in a book on aromatic molecules one year later. In 1985 this stable carbon molecule was actually observed in the mass spectrum of laser ablated graphite by Kroto. The direct stimulus to study carbon filaments of very small diameters more systematically came from the discovery of fullernes by Kroto and Smalley [28]. Wolfgan Kratschmer and Donald Huffman in 1990 showed that macroscopic amounts of solid $\mathrm{C}_{60}$ could be made using methods accessible to any 
laboratory by using a simple carbon arc to vaporize graphite instead of a high-power laser used by Kroto and Smalley [15].

The real breakthrough on carbon nanotube research came with Ijima's report of the experimental observation of carbon nanotubes using TEM [12].

\section{B. Fullerene $-\mathrm{C} 60$}

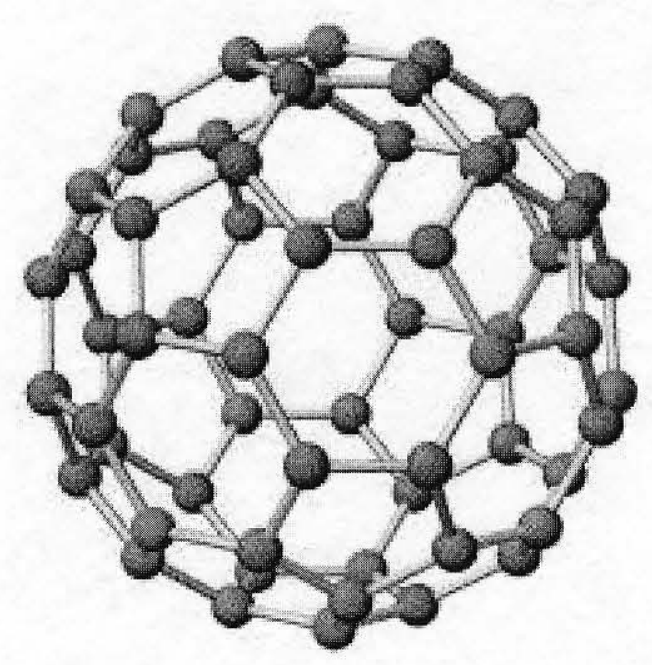

Figure 1 C60 molecule

In 1966, David Jones (in the New Scientist) discussed the possibility of creating graphite ballons similar to geodesic cages [2]. Fullerene, was discovered in 1985 by Kroto in an attempt to explain anomalous infrared ultraviolet carbon spectra from outer space [40]. Harry Kroto, of the University of Suseex, and Richard Smalley, of Rice University, Houston, had different reasons for being interested in the synthesis of carbon clusters. Kroto had been fascinated since the early 1960s in the processes occurring on the surfaces of the stars and believed that experiments on the vaporization of graphite 
might provide key insights into these processes. Smalley had been working on the synthesis of clusters using laser-vaporitation, concentrating chiefly on semiconductors such as silicon and gallium arsenide [15]. Later, Wolfgang Kratschmer, Donal Huffman and their coworkers finally found the method to prepare the microscopic quantities of this substance by using a simple carbon arc to vaporize graphite, again in an atmosphere of helium. Although before that time there was no evidence to prove the existence of this compound on the Earth [20]. This compound consisting of 12 pentagons and 20 hexagons with symmetry of a soccer ball, it forms a closed cage like the icosahedron of Leonardo Da Vinci's illustration for De Divina Proportione. This arrangement of carbon atoms was named "Buckminsterfullerene", "Fullerene" or simply “ Bucky Ball", honouring Buckminster Fuller who was the artist in designing geodesic done structures $[20,2,12]$.

\section{Fullerene Formation}

A possible mechanism for the formation of $\mathrm{C} 60$ was proposed which suggested that it might be a by-product of soot formation. It was later verified that $\mathrm{C} 60$ was indeed detectable during the soot formation process [2].

The early description of fullerene formation suggested that small carbon chains would grow by the sequential addition of carbon radicals. At a certain size ( $25-35$ atoms), it becomes favorable to form graphitic sheets. These planar fragments would have many dangling bonds around the periphery and some of them could be eliminated by incorporating pentagons. This allows the sheet to curve into a bowl-like form that closes upon itself. This atom-by-atom addition offers one pathway. Several mass spectroscopy experiments have demonstrated that fullerene formation is not a result of "tearing off" of 
graphitic fragments or ribbons during ablation and the subsequent closing of these fragments. To the contrary, isotope scrambling and a few other techniques have shown that the starting material is a single carbon atoms or ions [13].

Meijer and Bethune were able to identify $\mathrm{C} 60$ by mass spectrometry in the solid material deposited from a Smalley-type laser vaporization nozzle. The formation of fullerene by cyclodehydrogenation of a polyarene containing all sixty carbon atoms has been shown to occur under mass spectroscopic conditions. A similar approach employing macrocyclic polyalkynes has led to the formation of fullerene and fullerene under gas phase conditions. Glow discharge reactors have been used to pyrolyse chloroform resulting in the formation of fullerenes and chlorinated carbon clusters [4].

\section{Electronic Structure}

Fullerenes differ from the other forms of carbon in a fundamental way related to the hybridization of the atomic $\mathrm{s}$ and $\mathrm{p}$ levels. In diamond, $\mathrm{sp}^{3}$ hybidization assures a bond angle of $109^{\circ} 28^{\prime}$ and four identical bonds. The filling of the bonding states and the large separation between the $\mathrm{sp}^{3}$ bonding and antibonding levels results in an insulator (energy gap $\sim 5.5 \mathrm{eV}$ ). In graphite, $\mathrm{sp}^{2}$ hybridization produces three equivalent bonds, a bond angle of $120^{\circ}$, and strong planar bonding. The out-of-plane $p$ orbitals result in $\pi$ bonds and weak interplanar bonding.

In Fullerenes, the hybridization of the $\mathrm{s}$ and $\mathrm{p}$ orbitals is neither pure $\mathrm{sp}^{3}$ nor $\mathrm{sp}^{2}$, introducing a pyramidalization angle of $11.6^{\circ}$ for $\mathrm{C} 60$. Theoretical analyses have indicated that $\mathrm{C} 60$ is less stable than diamond or graphite by about $0.4 \mathrm{eV}$ per atom. The $\pi$ bonds are directed radially with a node on the nuclear cage. The fullerene solids are 
characterized as molecular crystals. As such, their orbitals are modified, by condensation to form solids. It has been pointed out by several authors that there are two different enegy scales, that they must be considered when considering the various electronics interactions.

One describes the overall electronic properties is large and defines on-ball electronic interactions. The occupied $\sigma$ and $\pi$ bandwidth is approximately $25 \mathrm{eV}$, and the bonding and antibonding $\pi$ bands extend over $\sim 20 \mathrm{eV}$. The other describes the broadening of the molecular orbit upon condensation into the solid state. This is much smaller, and estimates of the width for the bands derived from the highest occupied molecular orbitals (HOMO) or the lowest unoccupied molecular orbital (LUMO) are $\sim 0.5 \mathrm{eV}$ [13].

\section{E. An Introduction to carbon nanotubes}

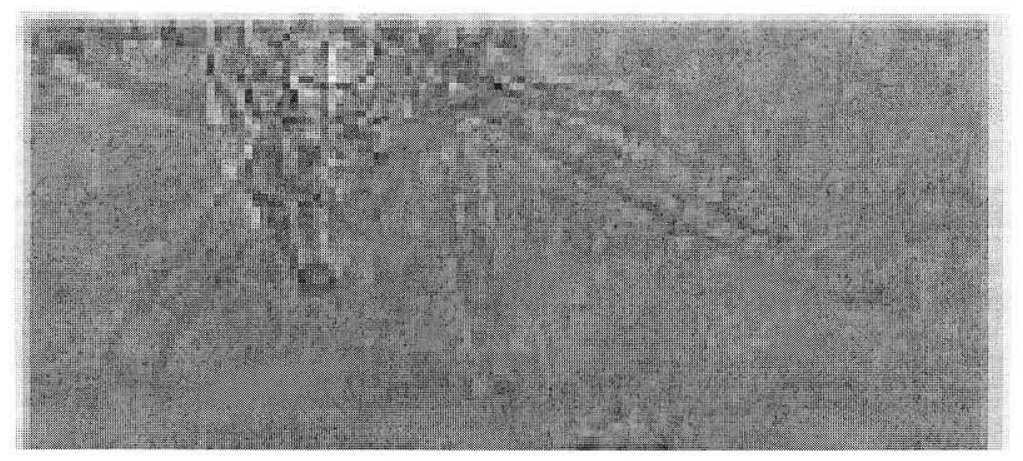

Figure 2 TEM image of SWNT

A "Carbon Nanotube" (CNT) is a tube-shaped material made of carbon that has a diameter measuring on the nanometer scale. A nanometer is one-billionth of a meter, or about one ten-thousandth of the thickness of a human hair. The graphite layer looks 
something like a rolled-up chicken wire with a continuous unbroken hexagonal mesh and carbon molecules at the apexes of the hexagons. In some cases, the hexagons are arranged in a spiral form. The pattern has an appearance similar to the Japanese art of bamboo basket weaving called Takekago [16]. Iijima first named the carbon nanotube a "micro-tubule." He later selected the name "carbon nanotube" from other name choices, including "microtubules," "tubulin" and "Iijimatubes" based on the nano size and the shape of a tube.

Carbon nanotubes have attracted the attention of the scientists from all over the world ever since the direct evidence by electron microscopy revealed the existence of carbon nanotubes [28]. The discovery of carbon nanotubes in 1991 captured the imagination and the attraction of physicists because of the carbon nanotubes electronic properties, of chemists because of their potential as "nanotest-tubes," of materials scientists because of their amazing stiffness, strength and resilience, and of private industry because of their multiple applications [15].

Carbon nanotubes have extremely interesting and unique chemical and physical properties. For example, SWNTs have very exciting mechanical properties and are predicted to be stronger than steel. The interior space of SWNTs can be used as one dimensional array elements, drug delivery, and fluidics. C60 molecules have been inserted with high efficiency in the interior of SWNTS by vapor phase reaction of C60 with SWNTs to form peapods (C60@SWNTs). Recent developments in large-scale synthesis of CNTs have accelerated applications of these materials in the area of electrical energy storage system. SWNTs have been used for electrodes of electrochemical energy storage [30]. Recently we have used SWNTs for electrodes of electrochemical energy storage 
systems such as supercapacitors, fuel cells, and lithium-ion secondary batteries, which we are currently working on. SWNTs are ultra sensitive enabling them to be used as ultrasensitive sensors. Combination of carbon nanotubes and ח-conjugated polymers has been investigated for making composite devises [39].

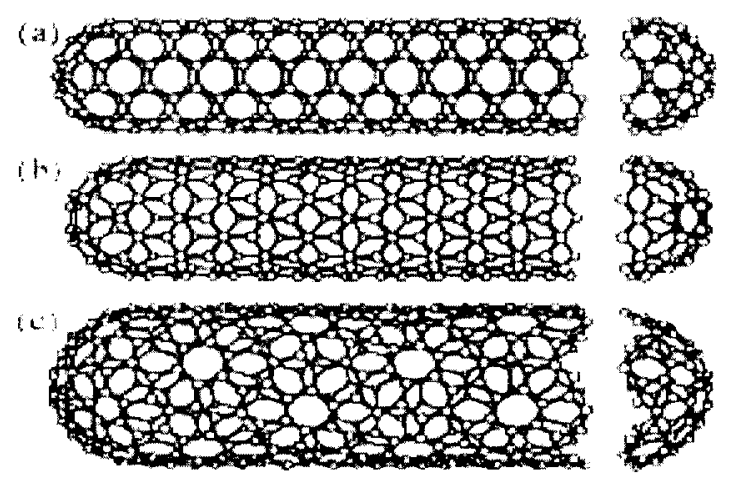

Figure 3 Classification of carbon nanotubes: (a) armchair, (b) zigzag, and (c) chiral nanotubes.

A single-wall nanotube is defined by a cylindrical graphene sheet with a diameter of a bout $0.7-10.0 \mathrm{~nm}$, though most of the observed single-wall nanotubes have diameters $<2 \mathrm{~nm}$. If we neglected the two ends of a carbon nanotube and focus on the large aspect ratio of the cylinder, these nanotubes can be considered as one-dimensional nanostructures [28]. The primary symmetry classification of a carbon nanotube is as either being achiral ( symmorphic) or chiral ( non-symmorphic). An achiral carbon nanotube is defined by a carbon nanotube whose mirror image has an identical structure to the original one. There are only two cases of achiral nanotubes; armchair and zigzag nanotube. The names of armchair and zigzag arise from the shape of the cross-sectional ring. Chiral nanotube exhibit a spiral symmetry whose mirror image cannot be 
superposed on to the original one [28]. The structure of a single-wall carbon nanotube can be described in terms of the chiral vector.

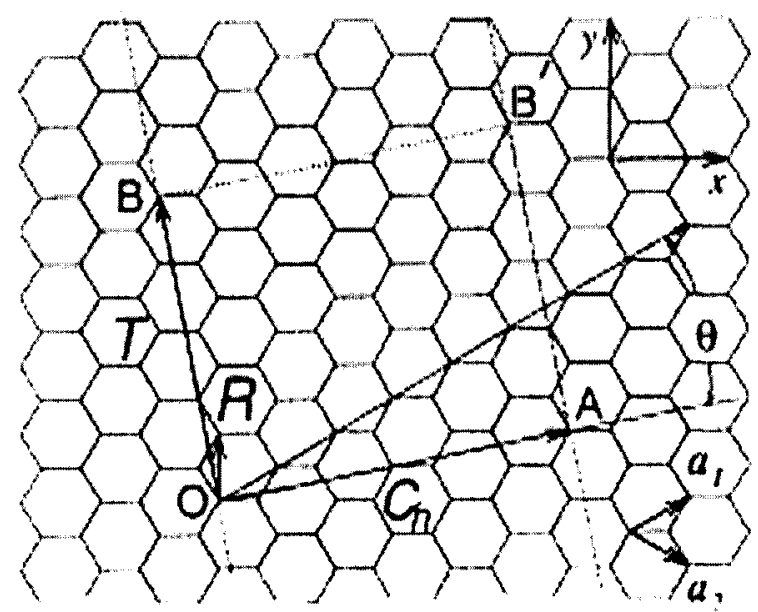

Figure 4 The unrolled honeycomb lattice of a nanotube. When we connect site $\mathrm{O}$ and $\mathrm{A}$, and $\mathrm{B}$ and B', a nanotube can be constructed. $\overrightarrow{O A}$ and $\quad \overrightarrow{O B}$ define the chiral vector $\mathrm{Ch}$ and the translation vector $\mathrm{T}$ of the nanotube, respectively [28].

$\mathrm{Ch}=\mathrm{n} \mathbf{a} 1+\mathrm{m} \mathbf{a} 2 \equiv(\mathrm{n}, \mathrm{m})(\mathrm{n}, \mathrm{m}$ are integers, $0 \leq|\mathrm{m}| \leq \mathrm{n})$

Show in the fig 4 ., where $\mathrm{n}$ and $\mathrm{m}$ are integers and $\mathbf{a} 1$ and $\mathbf{a} 2$ are the unit vectors $[28,10$, 21]. The chiral vector $\mathbf{C}_{\mathbf{h}}$ or $\mathbf{C}_{\mathbf{h}}=\mathrm{n} \mathbf{a}_{\mathbf{1}}+\mathrm{m} \mathbf{a}_{\mathbf{2}}$ is the vector in which the graphite sheet wraps around. As shown in Fig. 4 , the chiral vector $\mathbf{C}_{\mathrm{h}}$ connects two crystallographically equivalent sites $\mathrm{O}$ and $\mathrm{A}$ on a two-dimensional graphene sheet where a carbon atom is located at each vertex of the honeycomb structure. The lines $\overrightarrow{O B}$ and $\overrightarrow{A B}$ ' are both perpendicular to the vector $\mathbf{C}_{\mathbf{h}}$ at each end of $\mathbf{C}_{\mathbf{h}}$. In $(\mathrm{n}, \mathrm{m})$ notation for $\mathbf{C}_{\mathbf{h}}$ $=\mathrm{n} \mathbf{a}_{1}+\mathrm{m} \mathbf{a}_{2}$, the vectors $(\mathrm{n}, 0)$ or $(0, \mathrm{~m})$ denote zigzag nanotubes and the vector $(\mathrm{n}$, $n$ ) denote armchair nanotubes. The larger the value of $n$ the larger is the diameter of the tube. All other vectors $(\mathrm{n}, \mathrm{m})$ correspond to chiral nanotubes. Depending upon the rolling angle and diameter, nanotubes behave as semi conducting or metallic. The 
condition for metallic nanotubes is that $(2 n+m)$ or equivalent $(n-m)$ is a multiple of 3. In particular, the armchair nanotubes denoted by $(n, n)$ are always metallic, and the zigzag nanotubes ( $\mathrm{n}, 0)$ are only metallic when $\mathrm{n}$ is a multiple of 3. As in Fig 5 [28].

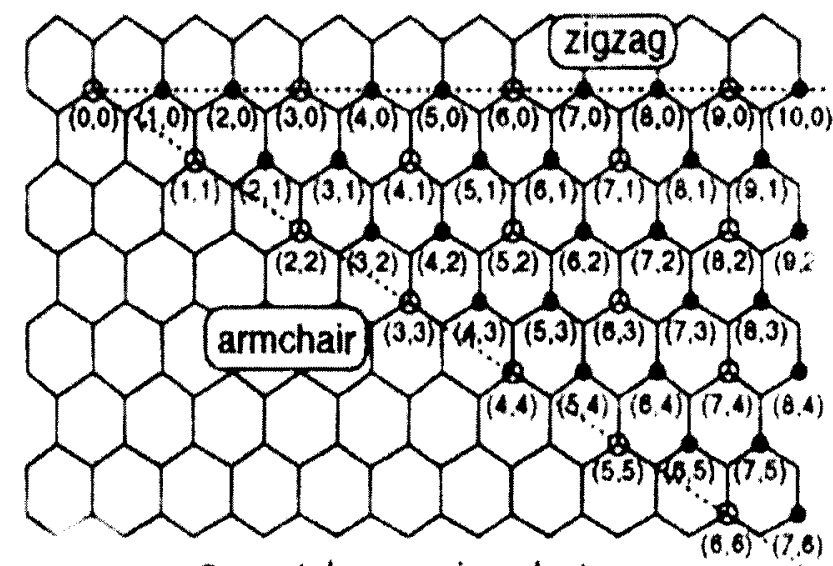

0 : metal : semiconductor

Figure 5 The carbon nanotubes $(n, m)$ that are metallic and semiconducting, respectively, are denoted by open and solid circles on the map of chiral vectors $(n, m)$ [28].

The nanotube diameter $\mathrm{dt}$ is given by

$d t=\sqrt{3} a_{c-c}\left(m^{2}+m n+n^{2}\right)^{1 / 2} / \pi=C_{h} / \pi$

where $\mathbf{C}_{\mathbf{h}}$ is the length of $\mathbf{C}_{\mathbf{h}}, a_{c-c}$ is the $\mathrm{C}$ - $\mathrm{C}$ bond length (1.42 $\left.\mathrm{A}^{\circ}\right)$ [10]. The chiral angle $\theta$ is given by

$\theta=\tan ^{-1}[\sqrt{ } 3 n /(2 m+n)]$

For all metallic nanotubes, independent of their diameter and chirality, it follows that the density of states per unit length along the nanotube axis is a constant given by 


$$
N\left(E_{F}\right)=\frac{8}{\sqrt{3} \cdot \pi \cdot a \cdot|t|}
$$

Where $a$ is the lattice constant of the grapheme layer and $|t|$ is the nearest-neighbor C-C tight binding overlap energy. In the figure (6) compares the density of states for metallic $(9,0)$ and semiconducting $(10,0)$ zigzag nanotubes. The density of states for a semiconducting nanotube near the Fermi level $\mathrm{EF}$ at $\mathrm{E}=0$ has a value of Zero, but is nonzero (and small) for metallic nanotubes [28].

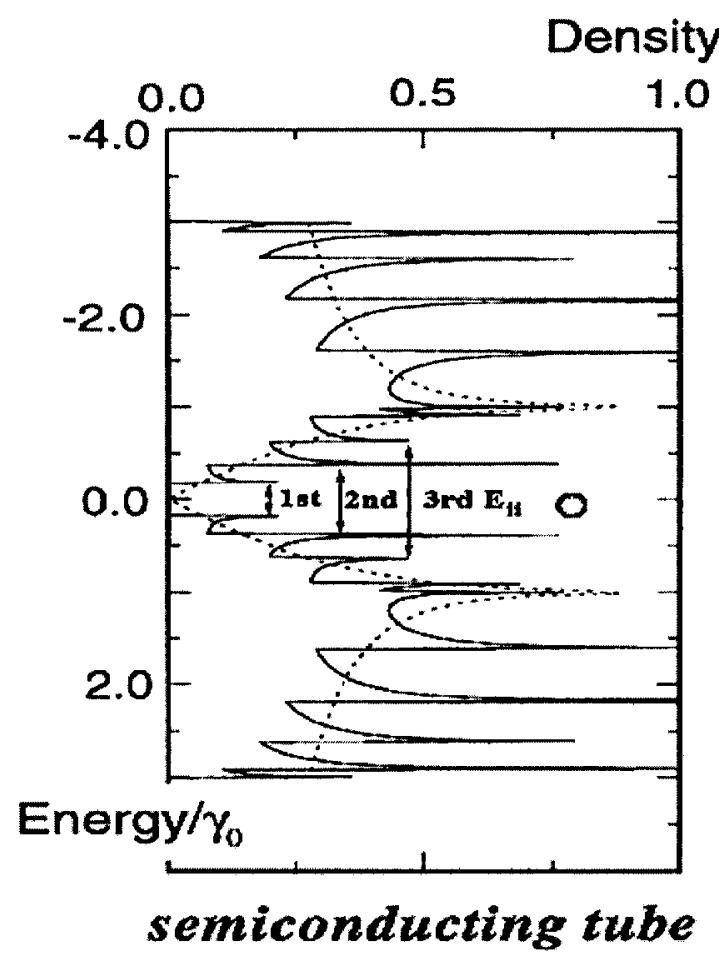

\section{of States}

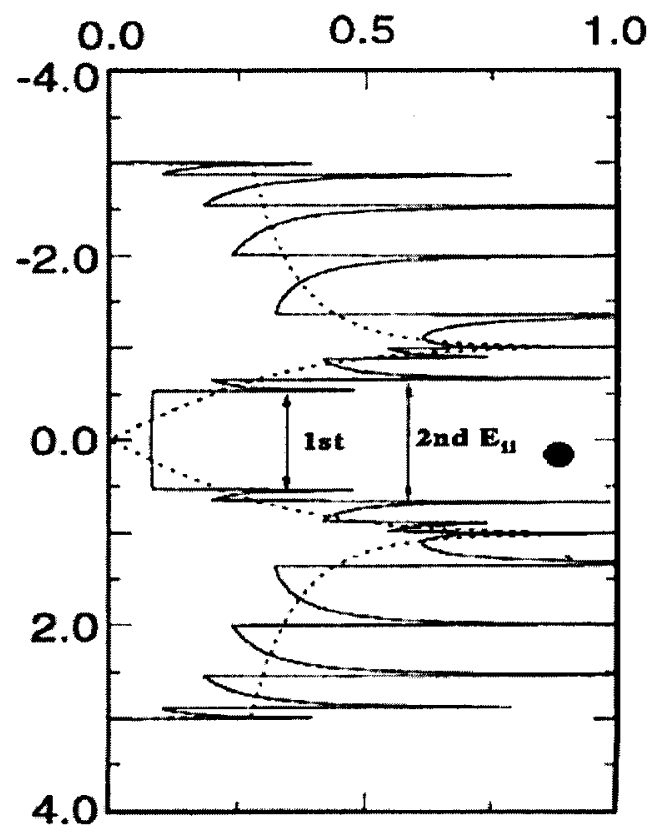

metallic tube

Figure 6 Density of states of semi-conducting and metallic tube

As the diameter of single wall carbon nanotube becomes small, the singularities in the electronic density of states (DOS) develop at particular energies as shown in Fig. 6. These singularities where the DOS becomes large are called van Hove singularities [10] characteristic of 1-dimensional systems. This behavior of DOS is totally different from 
bulk materials (3-D) and two-dimensional systems. Hence, the carbon nanotube DOS in the realm of small diameters show novel quantum behavior. The theoretical calculations have shown that for metallic nanotube, as shown in Fig. 6, there are finite numbers of DOS available around the Fermi energy whereas semi-conducting nanotube contains zero DOS at the Fermi energy $\left(\mathrm{E}_{\mathrm{F}}\right)$. This has been confirmed experimentally by scanning tunneling spectroscopy.

\section{F. Double-walled Carbon Nanotubes}

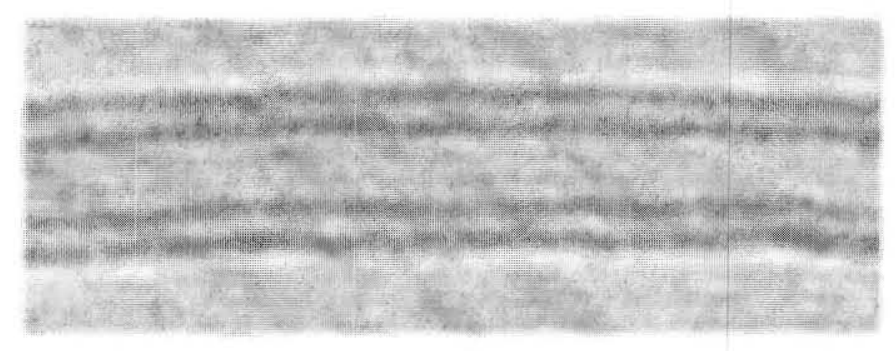

Figure 7 TEM image of DWNT

Double-walled carbon nanotubes (DWNTs) are a critical type of one-dimensional material between single-walled carbon nanotubes (SWNT) and multiwalled carbon nanotubes (MWNT) $[37,38,22]$. DWNT has been made experimentally by many methods, and consist of two concentric cylindrical graphene layers. The nucleation of the inner tube should occur after the growth of the outer. Thus, the inner tube diameter is determined by the outer tube one. A DWNT can be composed of a pair of inner and outer constituent layers with any chiralities, making different kinds of DWNTs, such as metalmetal, metal-semiconducting, or semiconducting-semiconducting nanotubes. It has been 
shown that the band structure of a DWNT depends on the combined configuration of the inner and outer tubes, but their stability depends only on their interlayer spacing. In order to examine the differences in detail, it is ideal to study double walled nanotubes (DWNTs). Several groups have reported their synthesis of DWNTs via different methods including arc- discharge, chemical vapor deposition ( CVD ) [38].

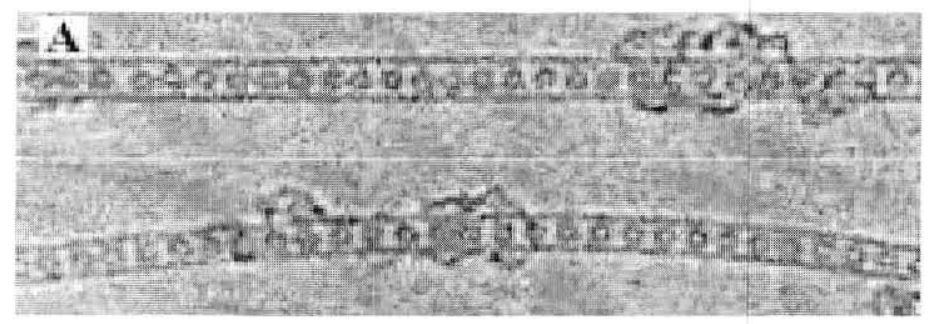

Figure 8 TEM image of peapod

C60 molecules have been inserted with high efficiency into the interior of SWNTs by vapor phase reaction of $\mathrm{C} 60$ with SWNTs to form peapods (C60@SWNT). It has been found that high temperature annealing of peapods at $1200{ }^{\circ} \mathrm{C}$ results in the coalescence among the C60 within the host SWNT. The fully packed C60 molecules inside SWNTs are completely transformed into a tubular structure forming DWNTs [ (Sumana ,3, 5]. Some groups have reported that the diameters of DWNTs grown in arc-discharge conditions in an $\mathrm{H} 2$ atmosphere were 3.5-6.5 nm [22], and high-quality DWNTs prepared in pulse arc-discharge exhibited the inner and outer diameters of $0.8-1.2 \mathrm{~nm}$ and 1.6- $2.0 \mathrm{~nm}$, respectively [22]. Another group has demonstrated that floating catalyst CVD can produce DWNTs in bulk. They found DWNTs with an inner diameter that varied from $0.4 \mathrm{~nm}$ to $2.2 \mathrm{~nm}$, while the outher tube diameter varied from 1.1 to $2.9 \mathrm{~nm}$ 
[6]. Hutchinson reported that DWNTs were produced by arc discharge technique with a catalyst mixture of $\mathrm{Ni}, \mathrm{Co}, \mathrm{Fe}$ and $\mathrm{S}$ in an atmosphere of $\mathrm{Ar}$ and $\mathrm{H} 2$ mixture at 350 Torr.

\section{G. Synthesis of Double Wall Nanotubes}

\section{Chemical Vapor deposition (CVD)}

John Cuming and his group utilized fumed alumina particle of size 13nm (Degussa Alumina C ) as a catalyst support material, and deposited iron salt onto the support from a methanol solution. Nanotube synthesis was initiated at approximately $900{ }^{\circ} \mathrm{C}$ in flowing Argon gas. As the alumina/iron salt mixture was heated, the iron salt forms iron oxide. To initiate the nanotube growth, the argon was replaced with flowing methane, After 10 minutes, the gas was switched back to argon and the sample was allowed to cool [9].

Other groups also synthesised DWNTs using the CVD method. Wei's group used methane as carbon source, ferrocene containing a small amount sulfur ( Fe:S=10:1, atomic ratio) was used as catalyst precursor, argon was used as carrier gas and the reaction temperature was above $1150^{\circ} \mathrm{C}$ [37]. Also Wei's group used Ferrocene and a small amount of sulfur ( $\mathrm{Fe}: \mathrm{S}=10: 1$ atomic ratio) dissolved in xylene to form a solution of $0.03-0.12 \mathrm{~g} / \mathrm{mL}$. The solution was injected by a syringe pump into a horizontal quartz tube. The reaction temperature was $1373{ }^{\circ} \mathrm{C}$ and the reaction time was about $10-20$ minutes [38].

Likewise, Lijie Ci and his group used the CVD method for the production of DWNTs. Ci's group used a two-stage furnace system fitted with a quartz tube (30 mm inner diameter). Ferrocene (Dicyclopentadienyl iron) and sulfur powder with an optimal 
molar ratio range of 8:1-192:1, were mixed uniformly and ground with a mortar. This mixture was used as catalyst and $\mathrm{C} 2 \mathrm{H} 2$ (acetylene, 8-12 sccm) was used as carbon source. The catalyst mixture was sublimed in the first furnace at a temperature of $60-90{ }^{\circ} \mathrm{C}$. The sublimed catalyst was carried by flowing argon (1200-1600 sccm) and $\mathrm{C} 2 \mathrm{H} 2$ mixture into the second furnace. The reaction temperature of the second furnace was $1100{ }^{\circ} \mathrm{C}[6]$.

\section{H. Synthesis of Double Wall Nanotubes in the Physics Laboratory}

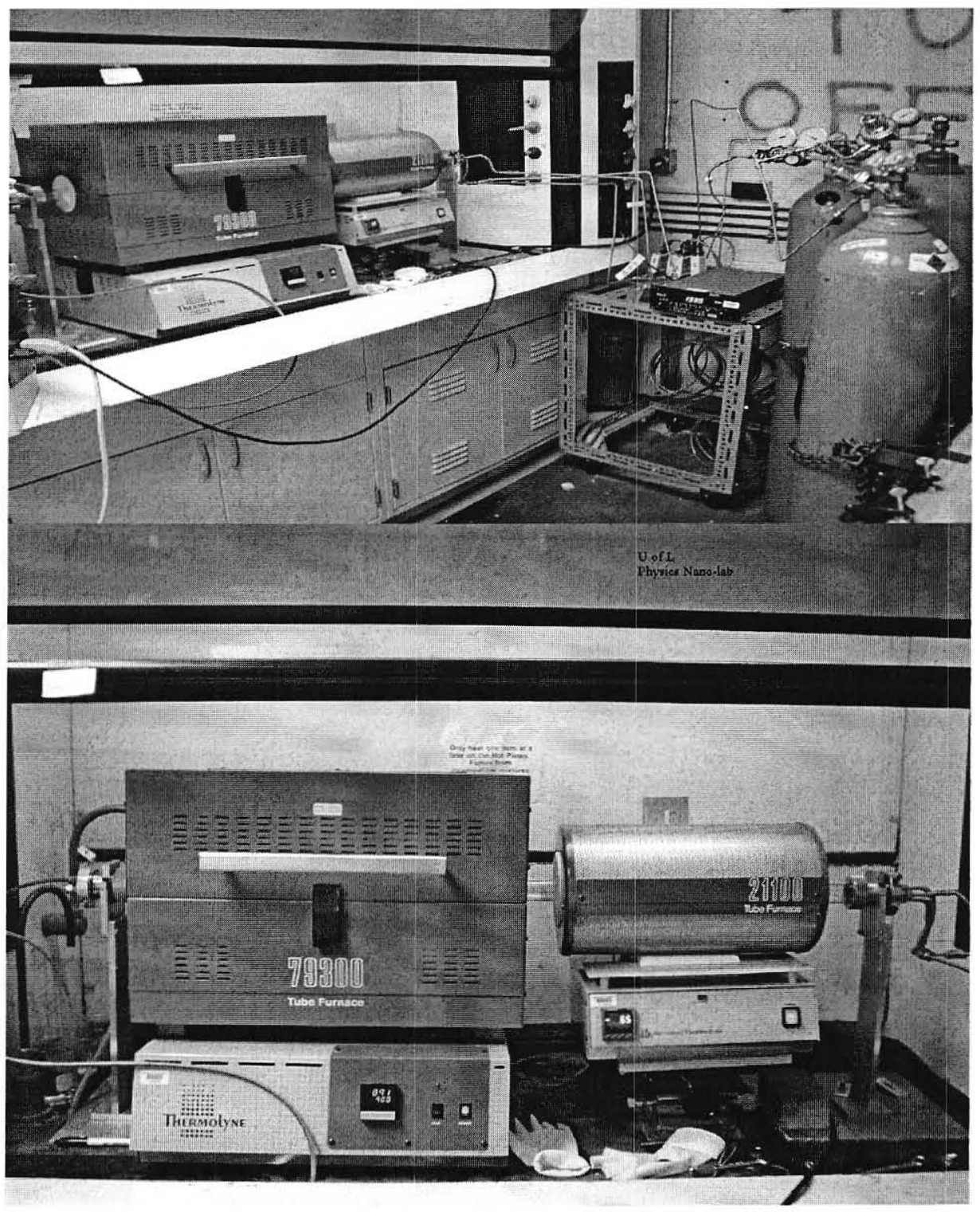

Figure 9 Physics Nano-lab DWNT Synthesis 
In our laboratory, we synthesized DWNTs by pyrolizing Methane on ferrocenesulfur floating catalyst particles in the CVD System. We use two-stage furnace system fitted with a quartz tube. Ferrocene ( dicyclopentadienyl iron ) $0.058 \mathrm{~g}$ and Sulfur $0.001 \mathrm{~g}$ ( $\mathrm{Fe}: \mathrm{S}=8: 1$ atomic ratio) were mixed with a mortar and this mixed powder was used as catalyst source. The catalyst source was sublimed in a small furnace at a temperature 90 ${ }^{\circ} \mathrm{C}$, at steps of $3{ }^{\circ} \mathrm{C}$ per minute, and kept at $90{ }^{\circ} \mathrm{C}$ for 2 hours. At the same time similar to the small furnace a second furnace was set to reach a temperature of $900{ }^{\circ} \mathrm{C}$ at steps of 30 ${ }^{\circ} \mathrm{C}$ per minute. Both smaller and larger furnaces reached the set point temperature almost simultaneously. The sublimed catalyst was carried by flowing Argon at a flow rate of 100 sccm and Methane, as the carbon source at a flow rate of $8 \mathrm{sccm}$ into the second furnace. The product was collected from the cooler part of the quartz tube and analyzed by micro Raman spectroscopy for characterizization.

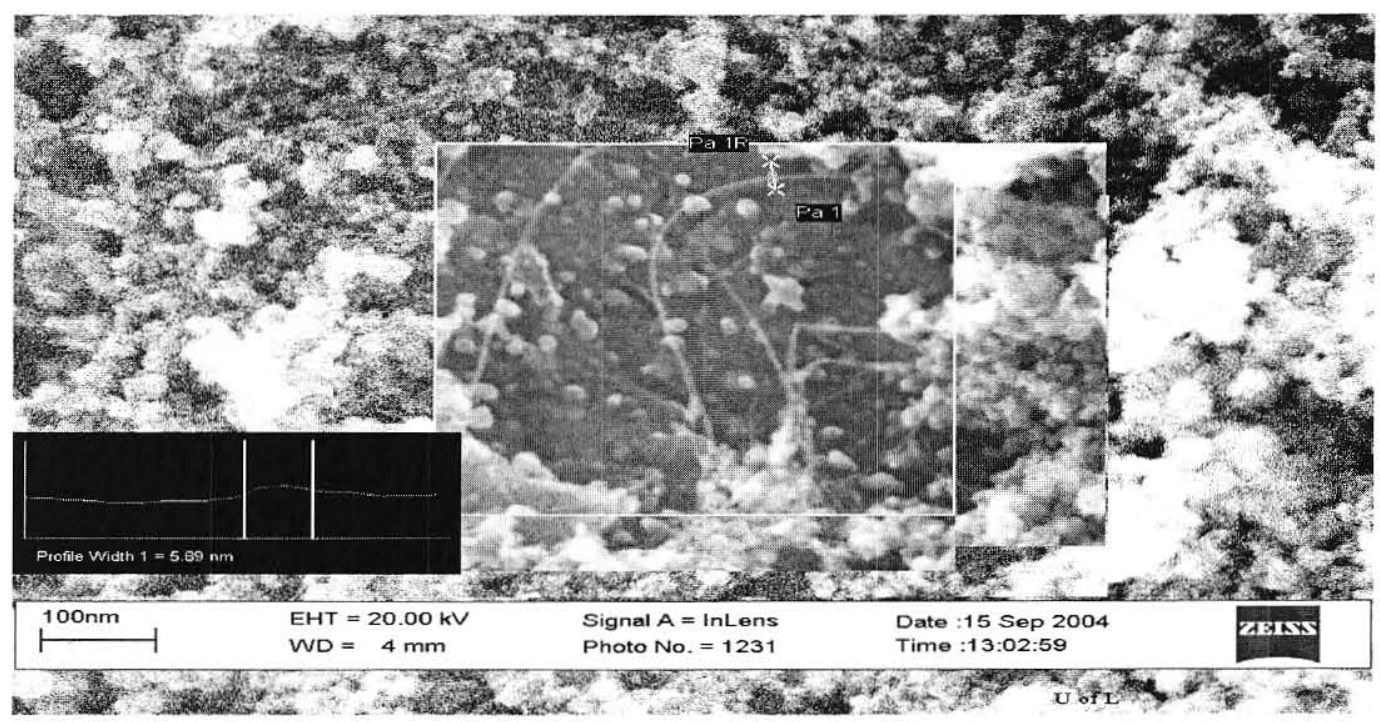

Figure 10 SEM picture of DWNTs width $5.89 \mathrm{~nm}$ 


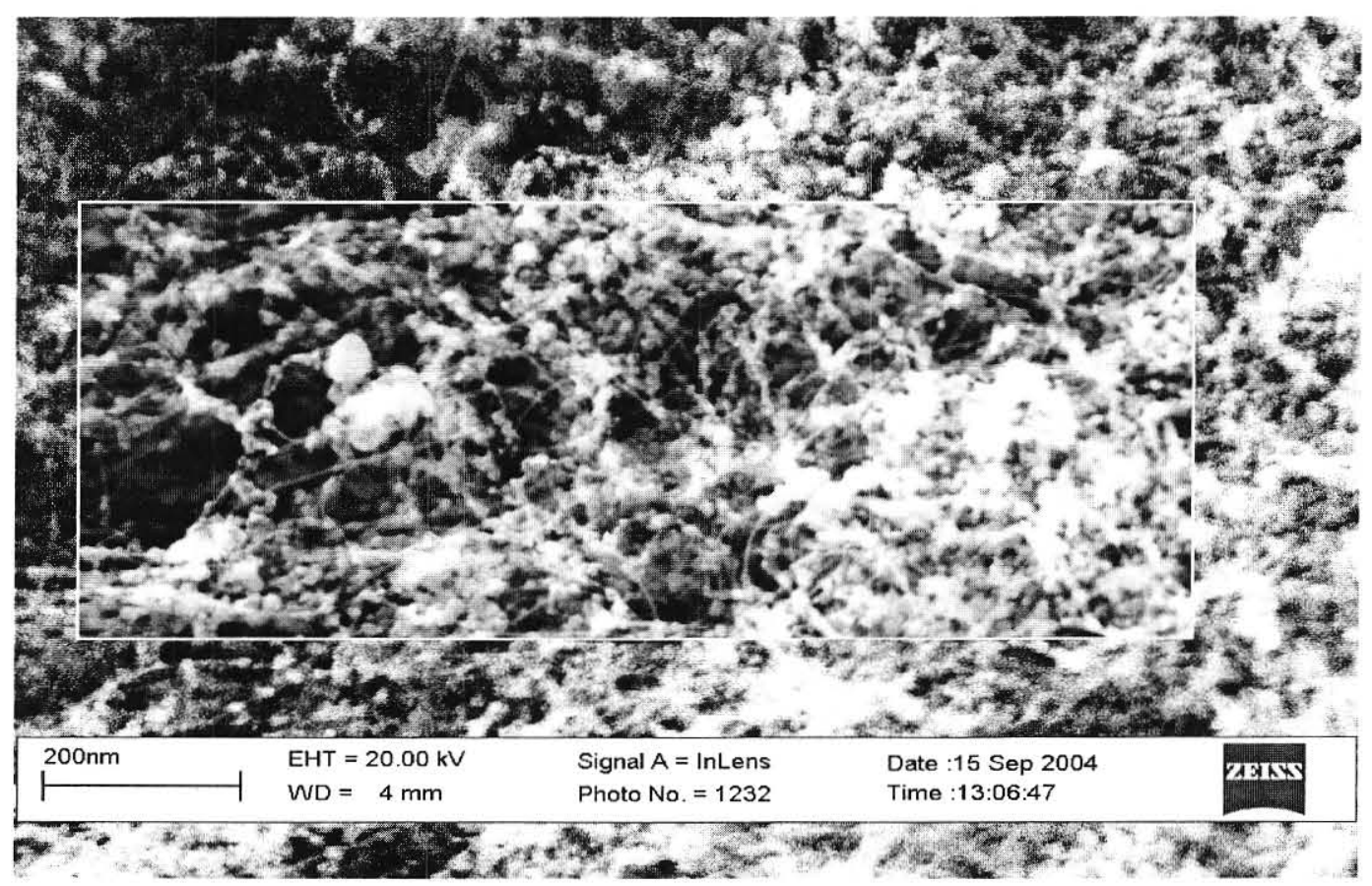

Figure 11 SEM picture of DWNT

\section{Raman Spectroscopic study on charge transfer}

In 1928 C. V. Raman discovered the inelastic phenomenon which bears his name and for it he was awarded the Nobel Prize for Physics in 1930.

Raman spectroscopy is a spectroscopic technique used to study vibrational, electronic, and other low-frequency modes in a system [18]. It relies on inelastic scattering, or Raman scattering of monochromatic light, usually from a laser in the visible, near infrared ( IR ), or near ultraviolet ( UV ) range. Phonons or other excitations in the system are absorbed or emitted by the laser light, resulting in the energy of the laser photons being shifted up or down. The shift in energy gives information about the phonon modes in the system. Typically, a sample is illuminated with a laser bean. Light from the illuminated spot is collected with a lens and sent through a monochromator. Wavelengths close to the laser line ( due to elastic Rayleigh scattering ) are filtered out and those in a certain spectral window away from the laser line are dispersed onto a 
detector. Raman spectrometers typically use holographic diffraction gratings and multiple dispersion stage to achieve a high degree of laser rejection. A photon-counting photomultiplier tube ( PMT ) or, commonly a charge couple devise (CCD) camera is used to detect the Raman scattered light [18].

Numerical experiments have been done on the Raman spectroscopy of the CNTs. In a common Raman spectrum of SWNTs, there are usually three features which are identified as radial breathing modes ( RBMs) (below $400 \mathrm{~cm}^{-1}$ ), D-band $(1300-1350$ $\mathrm{cm}^{-1}$ ) and T-band (tangential mode $\sim 1590 \mathrm{~cm}^{-1}$ ). The RBM of the SWNTs can be used to determine the diameters of the SWNTs. The D-band of the CNTs is mainly derived from the disorder carbon. [37]

The high-frequency Raman-active vibrations of $\mathrm{sp}^{2}$ carbon are sensitive to chemical doping. The C-C bond contracts (expands) for acceptor (donor). Single-walled carbon nanotubes ( SWNTs ) can be doped either $\mathrm{p}$ or $\mathrm{n}$ type [35].

The Raman in Fig. (12a) show the low-frequency radial breathing modes (RBMs) and the high-frequency tangential ( $\mathrm{T}$ ) modes Fig. (12b) for pristine and bromine-doped DWNT samples. The incident photon energy $\mathrm{E}=1.16 \mathrm{eV}$ can resonate with E22 in the in the outer semiconducting tubes and E11 in the inner semiconducting tubes simultaneously, where $E_{i i}$ is the energy difference between filled and empty Van Hove singularities. In the Fig. (12a), three low-frequency and three high-frequency RBMs are observed and assigned to the most dominant outer and inner shells using the formula.

$$
W_{R B M}\left(\mathrm{~cm}^{-1}\right)=\frac{234}{d\left(\mathrm{~cm} \cdot \mathrm{nm}^{-1}\right)}
$$

$W_{R B M}=$ Is the Radial Breathing mode frequency. 
$\mathrm{d}=$ diameter of nanotube

The proportional average constant is $\left(234 \mathrm{~cm}^{-1} \mathrm{~nm}\right)$ [5]. Other author use $(223.75$ $\left.\mathrm{cm}^{-1} \mathrm{~nm}\right)[3]$.
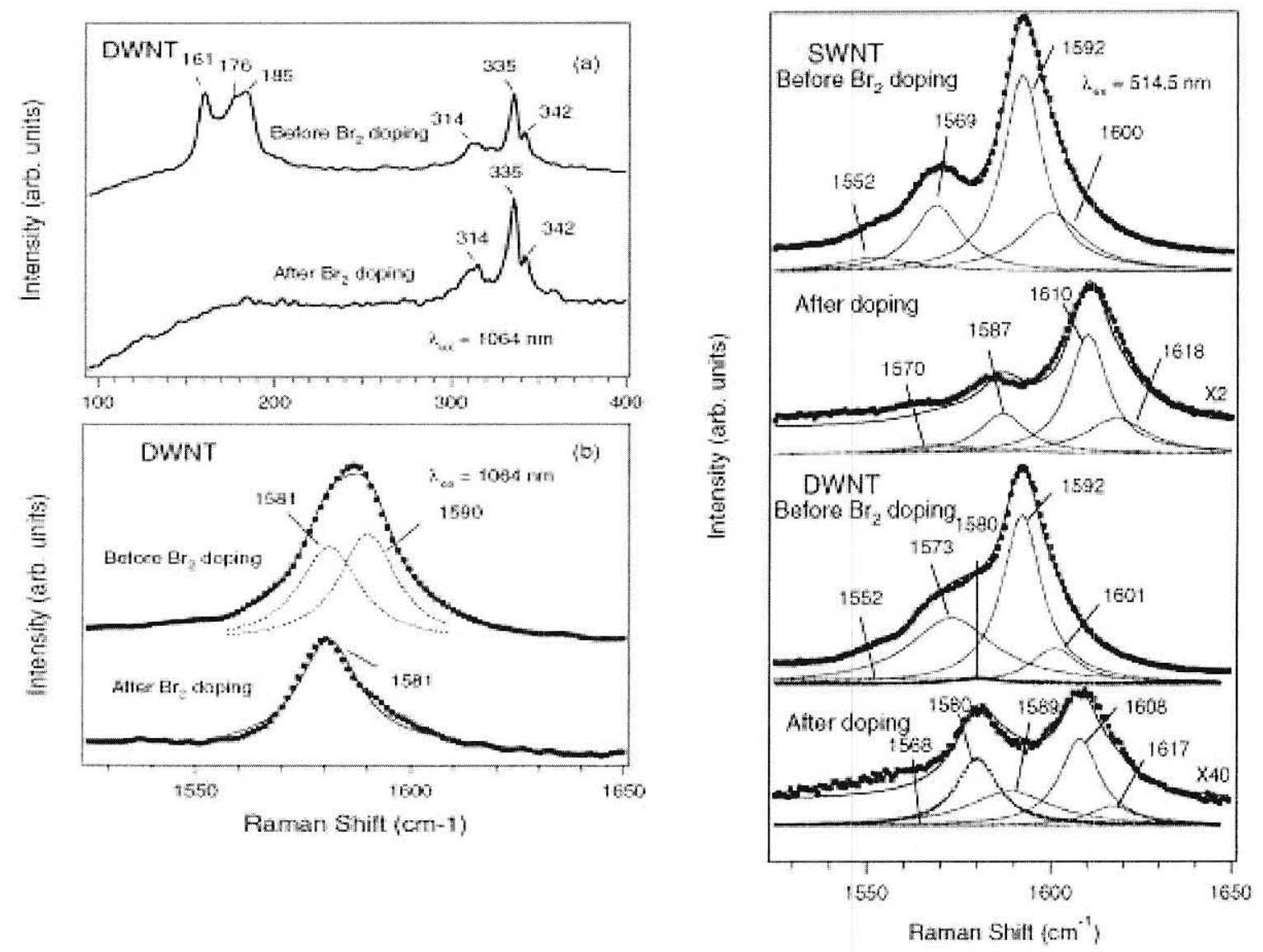

Figure 12. Raman scattering spectra of DWNTs using $1064 \mathrm{~nm}$ laser exicitation (a) Low frequenzy radial breathing mode (b) High frequency tangential mode.

Figure13. Raman scattering spectra of DWNT and SWNT tangential mode using $514.5 \mathrm{~nm}$ laser excitation.

The radial breathing modes of the outer tube are extinguished by $\mathrm{Br} 2$ doping, but the inner tube modes are essentially unaffected. Consistently, after Br2 doping, the inner tube T-band remains unaffected whereas the outer tube T-ban vanishes. The T-band spectrum of the doped SWNTs can be well fit by a simple rigid upshift $\left(\sim 18 \mathrm{~cm}^{-1}\right)$ of the pristine 
spectrum. Doped DWNT T-band (very weak) can be fit with rigidly upshifted four Lorentzians plus a $1580 \mathrm{~cm}^{-1}$ band for the inner tube.

The T-band and Radial breathing mode analysis indicated that positive charge on the DWNT is almost entirely deposited on the outher tube.

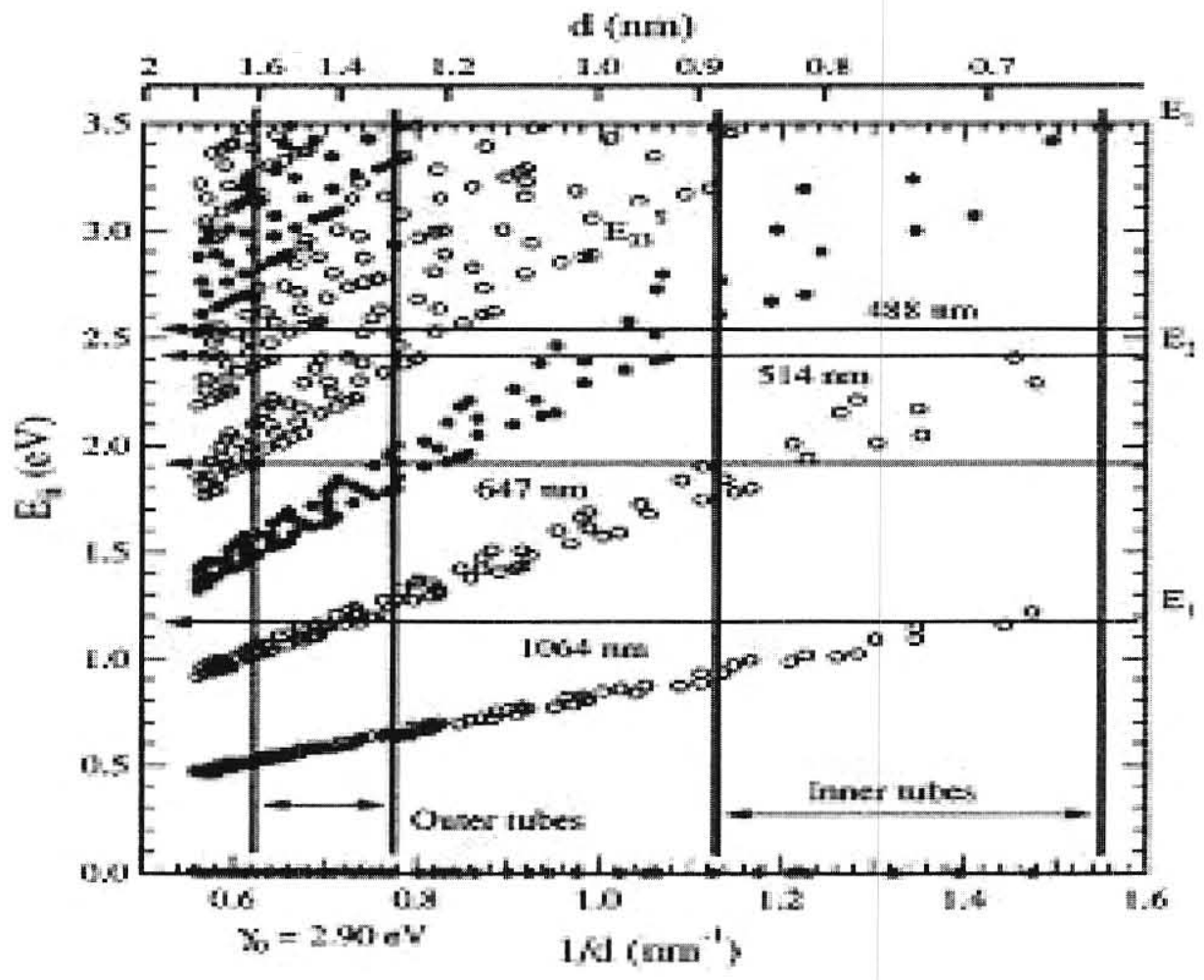

Figure 14. Tube diameter dependence of the energy separation between mirror image spikes of van Hove singularities.

\section{J. Synthesis of carbon nanotubes}

After the identification of carbon nanotubes in 1991 further stimulated work in the field was needed to follow. SWNTs were generally found along with larger concentrations of amorphous carbon, carbon nanoparticles and other carbon nanomaterials, and the single-walled constituents contained a distribution of diameters and chiral angles [28]. 
The detailed mechanism responsible for the growth of these nanotubes is not yet well understood. Soon after the publication of the laser vaporization method for the synthesis of single-wall carbon nanotube ropes, another synthesis route was found for the synthesis of gram quantities of single-wall carbon nanotubes, using the carbon arc method [28]. There are several methods for the growth of single walled and multi walled carbon nanotubes. Chemical vapor deposition method (CVD) can be carried out at either atmospheric or low pressures [36], and is a highly promising method for growth of high quality nanotubes at large scale [10]. Both SWNTs and MWNTs can be grown by this method. MWNTs growth use ethylene or acetylene as a source of carbon and typical growth temperature is in the range $550-750{ }^{\circ} \mathrm{C}[10]$. For the growth of SWNTs typically higher temperatures, $850-1000{ }^{\circ} \mathrm{C}$ are suitable for the methane CVD [10]. Methane is used as a carbon source because it is highly stable at higher temperatures against selfdecomposition compared to other hydrocarbons.

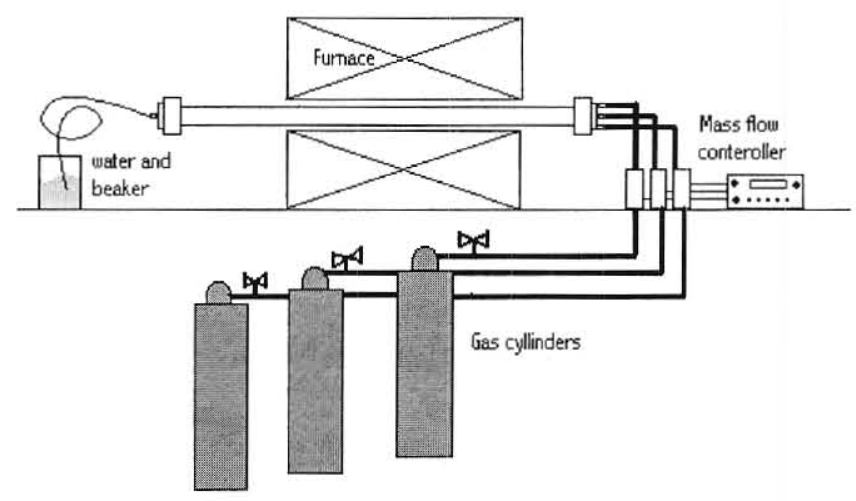

Figure 15. CDV schematic [18]. 
CVD method basically requires a tube furnace and carbon source such as Methane, Ethylene etc. and catalyst nanoparticles such as Fe, Co, Ni. As shown in fig. 15 the gas containing carbon (feedstock) is passed through the quartz glass tube encapsulated by the furnace. The substrate containing metal nanoparticles is seated inside the tube within the furnace. The gas dissociates at the catalytic particle sites and the dissociated carbon atoms dissolve in the metal nanoparticles and finally saturate [10]. Then carbon nanotubes start growing on the nanoparticles. The nanotubes are collected when the system is cooled down. The nanotube structure is favored over other forms of carbon because there are no dangling bonds on the tube, and so they are in a low energy form as opposed to graphite sheet [10]. In 1972, Baker and co-worker gave a detailed insight into the mechanism of filament growth by the application of controlled atmosphere electron microscopy (CAEM). This work demonstrated that filament growth involved the deposition of carbon behind an advancing metal particle [15]. Transition metal nanoparticles are used as catalyst because carbon atoms have finite solubility in these metals at high temperatures and hence are suitable for the nanotube growth mechanism. There are two basic modes for the growth of carbon nanotubes in CVD [10]. It is assumed that the catalyst particles are spherical or pear-shape, in which case the deposition will take place on only one half of the surface (this is the lower curvature side for the pear shape particles) [9]. In the "base growth" method, the metal catalyst particles stick with the supporting material due to strong interactions and thereby growing the tube onto the metal particle by providing the carbon from the base. Whereas for the "tip growth" method, the metal particle lift off from the support and goes along the growth of the tube [10]. In tip growth, the particle detaches and moves at the head. The carbon is 
supplied from the tip during the growth of the tube. Hence, Metal support interactions play an important role in growth mechanism of nanotubes $[9,24]$.

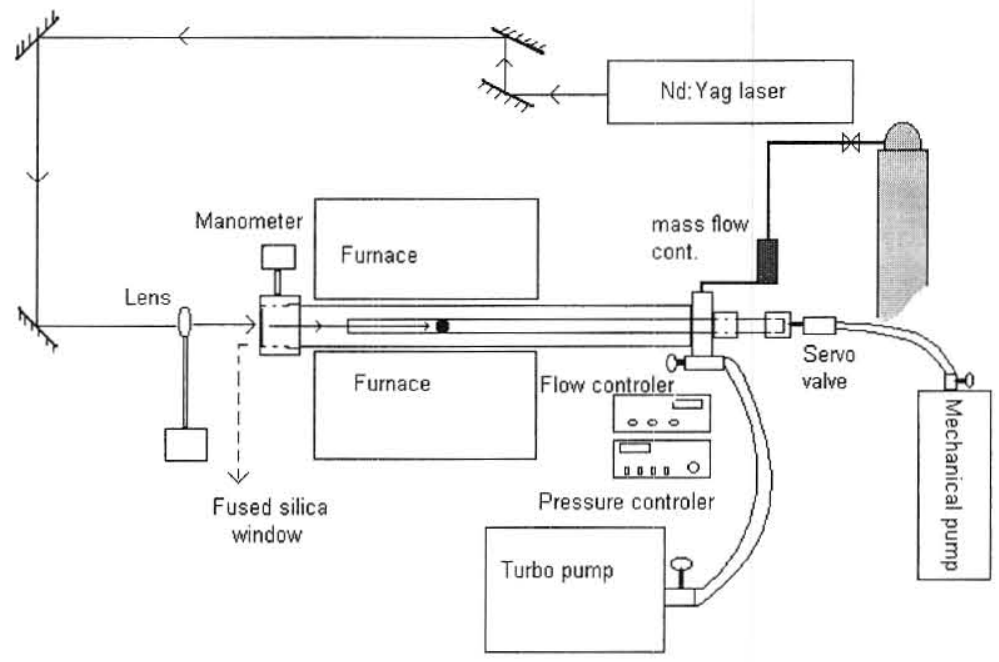

Figure 16. Schematic of pulse laser vaporization system [18].

Another method for the growth of carbon nanotubes is Pulsed Laser Vaporization (PLV technique). This technique grows the purest SWNTs. PLV basically requires a pulsed laser, a solid target containing graphite and catalysts, and a furnace as shown in Fig. 16. The target, which is seated inside a quartz glass tube within the furnace, is composed of compacted graphite and catalytic nanoparticles ( $\mathrm{Y}, \mathrm{Ni}, \mathrm{Co})$. The glass tube, which is placed in a tube furnace, is heated. The energy to dissociate and to release carbon atoms from graphite is provided by means of laser pulses. The pulsed laser is moved across the target in raster fashion, which evaporates the graphite. The inert gas flow is passed through the tube, which carries the nanotubes from the hot zone and hence condenses them onto the cold collector outside the furnace zone. 


\section{K. Purification of carbon nanotubes}

Methods for purification of SWNTs by metal catalyzed oxidation have been developed.

Oxidative treatment of the SWNTs removes amorphous carbon [27]. The disadvantage of oxidation is that not only the impurities are oxidized, but also the SWNTs. A reason why impurity oxidation is preferred is that these impurities are attached to the metal catalyst, which also acts as oxidizing catalyst. Acid treatment is another method for purification of SWNTs. The acid treatment will remove the metal catalyst. First, the surface of the metal must be exposed by oxidation or sonification. The metal catalyst is then treated with acid and solvated $[9,7,27]$.

Eklund's group at Pennsylvania State University has developed a technique for the purification of SWNTs by a selective oxidation step at $425^{\circ} \mathrm{C}$ in dry air for $\sim 20 \mathrm{~min}$. This removes amorphous carbon and weakens the carbon shell covering the metal catalyst. Then by a $28 \mathrm{hr}$. acid reflux in $4.0 \mathrm{M} \mathrm{HCl}$ to remove the metal residue [27].

\section{Ultrasonication}

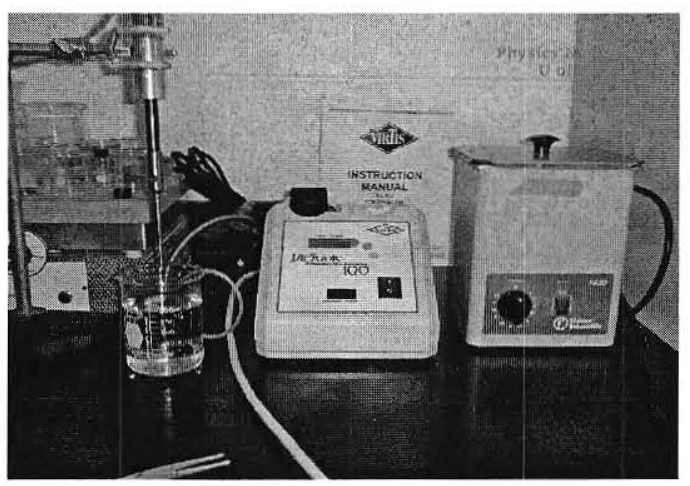

Figure 17 Ultrasonic set. 
Ultrasonic vibrations separate the agglomerates of different nanoparticles. It will force to vibrate and will become more dispersed. The separation of the particles is dependent on surfactant, solvent and reagent used.

\section{Annealing}

Another way of purification of nanotubes is annealing. Due to high temperatures (400 to $\left.1200{ }^{\circ} \mathrm{C}\right)$ the SWNTs defects are fixed and the nanotubes is rearranged. The high temperature also causes graphitic carbon and the short fullerenes to pyrolyse.

\section{Purification of raw carbon nanotube material synthesized by arc discharge method}

Nanotubes produced by the arc discharge method using Ni-Y catalyst are subjected to a post- synthesis chemical purification. This is done in a two-step process

(i) Oxidation in dry air for $30 \mathrm{~min}$. at $350{ }^{\circ} \mathrm{C}$ followed by

(ii) Reflux in $4 \mathrm{M} \mathrm{HCl}$ at $\mathrm{T}=120^{\circ} \mathrm{C}$ for $4 \mathrm{hrs}$.

Step (i) is designed to oxidize the amorphous carbon by conversion to $\mathrm{CO}$ and to weaken the carbon passivation coating over the Ni-Y catalyst particles. The metal (Ni-Y) content of the purified sample can be determined by oxidizing the sample in air in a thermogravimetric analyzer to be 2 at.\%. A typical value for residual metal content in purified material has been found to be less than $1 \mathrm{wt} . \%$. The purified sample was finally subjected to a vacuum degas at $1000^{\circ} \mathrm{C}$ at $10-7$ Torr for $24 \mathrm{hrs}[35,9,24]$.

\section{The chemical purification of the PLV used in this study}

The SWNTs used in this study were prepared using pulsed laser vaporization (PLV) of a graphite target containing $\mathrm{Fe} / \mathrm{Ni}(0.6 \%-0.6 \%$ atomic $)$ catalysts. The chemical purification of the PLV derived material was carried out by refluxing in $70 \% \mathrm{HNO} 3$ for 
$8 \mathrm{~h}$ at $160^{\circ} \mathrm{C}$. The suspension was neutralized by centrifugal decantation with distilled water and finally with ethanol. Then the purified SWNTs were dried and heated in dry air at $420^{\circ} \mathrm{C}$ for $20 \mathrm{~min}$. This last treatment was found to be necessary for opening the tube ends to allow the dopants to easily creep into the nanotubes.

\section{Applications of carbon nanotubes}

Carbon nanotubes have unique structures and tunable properties and they become a key material in ultra fine devices, for use in transistors, very-sensitive sensors, nanoprobes, high resolution AFM probes, pharmaceuticals, lithium intercalation, field emitting devices, electrochemical supercapacitors, composite materials, and fuel cells.

\section{Carbon nanotube field emitters}

Carbon nanotubes can be used for emission of electrons. Since a nanotube has a very sharp tip, it requires a very weak field to emit electrons. For technological applications, the emissive material should have a low threshold emission field and high stability at high current density. In addition, an ideal emitter is required to have nanometer size diameter, high electrical conductivity, structural integrity, a small energy spread and great chemical stability. Carbon nanotubes posses all these properties. Carbon nanotubes can therefore be used as field-emitting devices in flat panel displays, gas-discharge tubes in telecom networks, electron guns for electron microscopes, AFM tips and microwave amplifiers.

\section{Carbon nanotube field effect transistor}

The field-effect transistor can be constructed with only one semi-conducting SWNT. By applying a voltage to a gate electrode, the nanotube can be switched from a conducting to 
an insulating state. Carbon nanotube transistors can be coupled, working as a logical switch, the basic component of computers.

On oxidized silicon wafers, large arrays of typically gold electrodes are fabricated using e-beam lithography, metal evaporation and lift off techniques. The nanotube material, which consists of ropes of SWNTs, is ultrasonically dispersed in to dichloroethane solution and then spread onto the fabricated electrodes. Images are taken by Atomic Force Microscopy. Fortunately, there may be a nanotube connecting two metal electrodes. The two electrodes works as Source and Drain and the nanotube works as a channel. Due to ballistic transport of electrons through the nanotube channel, more current flows from source to drain, compared to other under FET and hence more transconductance is obtained.

\section{Carbon nanotubes as a highly sensitive chemical nanosensor}

Carbon nanotubes are very sensitive to various gases. They change the thermopower and the electrical resistivity when exposed to various kinds of gases [34]. Due to this kind of behavior, they can be utilized as thermoelectric nanonose or chemical sensor. Our studies of adsorption and desorption of various gas molecules by ropes of SWNTs may aid in the development of such thermoelectric nanosensor.

\section{Energy Storage}

Carbon nanotubes are considered for energy production and storage. Graphite carbonaceous materials, carbon fiber and carbon nanotubes are used in batteries, electrochemical applications, and fuel cells [10]. Advantages of using nanotubes for energy storage are their small dimensions, smooth surface topology and perfect surface 
specificity. The rate of the electron transfer at carbon electrodes determines the efficiency of the fuel cells [10].

\section{Hydrogen and ion storage}

Single Wall Nanotubes may have important applications in hydrogen storage. The study of hydrogen storage in carbon nanotubes remains active and controversial. Extraordinarily high and reversible hydrogen adsorption in SWNT containing materials and graphite nanofibers has been observed and has attracted considerable interest in both academia and industry $[10,1]$. Due to high surface area, carbon nanotubes can store hydrogen efficiently in the various adsorption sites and can liberate it slowly into fuel cells. The advantage of hydrogen as energy source is that its combustion product is water. The two commonly used means to store hydrogen are gas phase and electrochemical adsorption.

Because of their cylindrical and hollow geometry, and nanometer scale diameters, it has been predicted that carbon nanotubes can store a liquid or gas in the inner cores through a capillary effect.

\section{Lithium ion battery}

The key element that makes nanotubes so potentially useful as electrochemical storage devices is their structure. Carbon nanotubes, which are formed when a graphene sheet is curled up into a cylinder and the carbon atoms joined seamlessly to each other. Carbon nanotubes typically aggregate into bundles, termed ropes. These ropes are expected to display superior energy storage capabilities provided that the $\mathrm{Li}$ ions can be intercalated both into the channels between the nanotubes, and into the interior of the nanotubes 
themselves. The key to superior battery performance using nanotubes lies in the ability of $\mathrm{Li}$ ions to enter and leave the nanotube interiors at a reasonable rate [23].

The lithium ion battery system is commonly used in high energy density applications. The lithium ion battery is targeted to fulfill the requirements for future applications like electric vehicles and biomedical devices such as an artificial heart [36].

The basic principle of rechargeable lithium batteries is electrochemical intercalation and de-intercalation of lithium in both electrodes. An ideal battery has a high-energy capacity, fast charging time and a long cycle time. The capacity is determined by the lithium saturation concentration of the electrode materials. SWNTs have shown to posses both highly reversible and irreversible capacities [10].

\section{Supercapacitors}

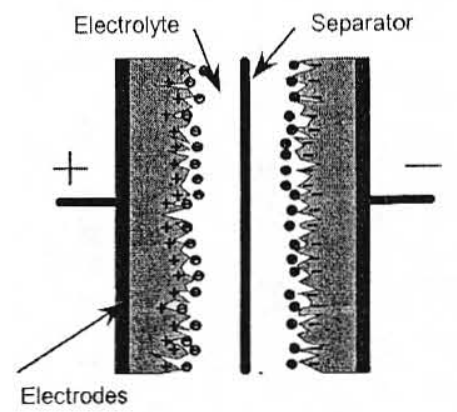

Figure 18 Supercapacitor sketch

Supercapacitors are energy storage devices with very high capacity, a low internal resistance, long cycling life and are free from toxic materials [19]. The two electrodes are separated by a membrane, the separator, which allows mobility of the charged ions but forbids the electronic conduction. This composite is subsequently rolled or folded into a cylindrical or rectangular shape and stacked in a container. Then the system is impregnated with an electrolyte Figure 18 [26]. The capacity of an electrochemical 
supercapa-inversely depends on the separation between the charge on the electrode and the counter charge in the electrolyte. Because this separation is about a nanometer for nanotubes in electrodes, very large capacities result from the high nanotube surface area accessible to the electrolyte. In this way, a large amount of charge injection occurs if only a small voltage is applied. This charge injection is used for energy storage in nanotube supercapacitors.
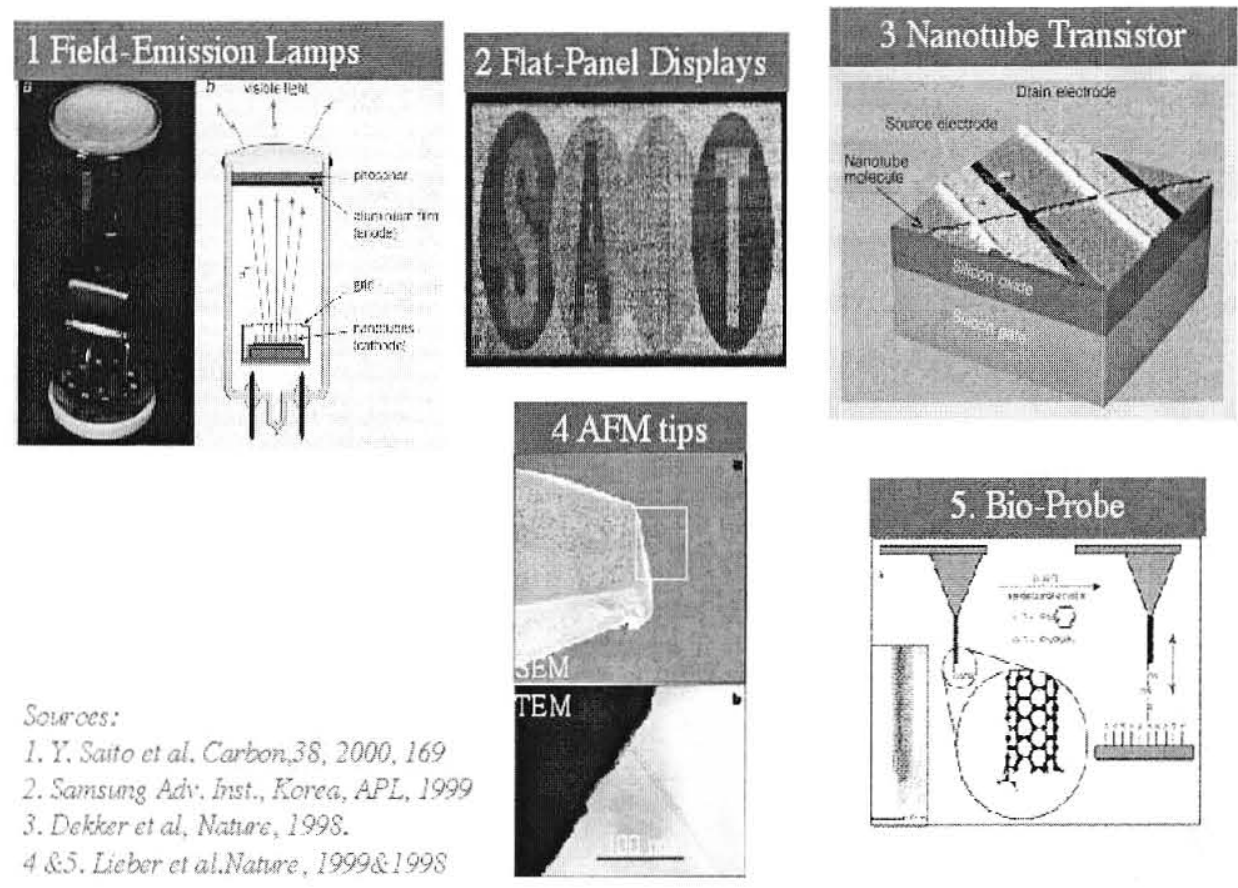

Sotros:

1. Y. Sauto et al. Carbon, $38,2000,169$

2. Samsung Adv, Inst., Korea, APL, 1999

3. Dekker et al, Natiac, 1998.

$4 \& 5$. Lieber et al. Nature, $1999 \$ 1998$

In Figure 19 shows five devices based on nanotubes already in early stages of commercialization [24]. 


\section{CHAPTER II}

\section{MEASUREMENT SYSTEM: THE THERMOPOWER AND DC FOUR-PROBE ELECTRICAL RESITANCE.}

\section{A. Introduction}

The fundamental properties and possible applications of single wall carbon nanotubes (SWNT) have developed into a large international activity. It has been directed toward study of their physical properties, including their chirality-dependent electrical resistivity, quantum transport and mechanical properties [32]. In particular, the thermoelectric properties of mats of SWNTs have been shown to be extremely sensitive to environmental gases. Thermopower and resistivity measurements have been interpreted as evidence that SWNTs can be easily doped by ambient exposureto $\mathrm{O} 2$, forming charge transfer complex $\mathrm{C}^{+\delta}-\mathrm{O}_{2}^{-\rho}$.

These results demonstrate that large positive thermopower data are not intrinsic, but rather are the result of $\mathrm{O} 2$ exposure [34]. In addition, there has been recently reported a charge transfer property between bromine and DWNTs. Alkali-doped buckypaper exhibits metallic P (T) [17]. Therefore, the reaserch in this study is focused into the doping- induced change of thermopower or Seebeck coefficient $\mathrm{S}$ and the four probe resistance by exposing SWNTs, DWNT, and C60@SWNTs to potassium. It was necessary to modify the thermoelectric probe and electronics and from the previous study. 
A simple analog subtraction circuit consists of four instrumentation amplifiers was used to measure the thermoelectric power of entangled bundles of SWNTs. This method is know as a heat pulse method. In addition, the four probe electrical resistivity of the sample was measured by simply adding two more terminals for voltage measurements to the sample. The four probe resistance $\mathrm{R}$ was studied in a quartz reactor with; 20-mm inner diameter, $\sim 25 \mathrm{~cm}$ in length equipped with a $23 / 4-$ in. knife-edge flange sealed via $\mathrm{Cu}$ gasket to a standared multipin feed-though flange. For in situ transport measurements, two Chromel Alumel (K-type) thermocouples and two additional $\mathrm{Cu}$ leads were attached with small amounts of silver epoxy to the four corners of the $4 \mathrm{~mm}$ x $4 \mathrm{~mm}$ sample to measure the TEP and the DC four-probe electrical resistance simultaneously. One end of the sample was attached to the heat sink, which was in thermal contact with the resistive heater. The computer triggering applied a voltage pulse across the heater produceing a heat pulse. The heater was a simple resistor and it connected with the voltage pulse generator makes a heat pulse generator circuit. The heater supplies the heat pulse to induce temperature across the sample.

\section{B. An Introduction to Seebeck Coefficient (Thermopower)}

Thomas Johann Seebeck (1770-1831), a Physician, an Estonian-Born. In 1821, Seebeck, accidentally joined semicircular pieces of bismuth and copper while studying the thermal effects on galvanic arrangements. Seebeck experimented repeatedly with different metal combinations at various temperatures and he describes that effect as “ Thermomagnetism" [14]. If we take a conductor and place one end of it into a cold place and the other end into a warm place, energy will flow from the warm to cold part. The 
energy takes the form of heat. The intensity of the heat flow is proportional to the thermal conductivity of the conductor. In addition, the thermal gradient establishes electric field inside the conductor. The field results in incremental voltage [14]:

$d V=S \frac{d T}{d x} d x$

$\mathrm{dT}=$ The temperature gradient across a small length $\mathrm{dx}$

$\mathrm{dx}=$ Small length

$\mathrm{S}=$ Is the absolute Seebeck coefficient of the material. If material is homogeneous, $\mathrm{S}$ is not a function of length and it reduces to

$d V=S d T$ It is Mathematical expression of thermoelectric effect.

In order to observe thermoelectricity, it is necessary to have a circuit composed of two different materials, and we can then measure the net difference between their thermoelectric properties [14]. Moreover, thermopower ( $\mathrm{S}$ ) is a bulk property of the material. Thermopower, which is also called Seeback coefficient, is the potential difference $\Delta \mathrm{V}$ (Open circuit voltage) developed by the temperature difference $\Delta \mathrm{T}$ over the material.

$S=\frac{\Delta V}{\Delta T}$

\section{Thermocouples}

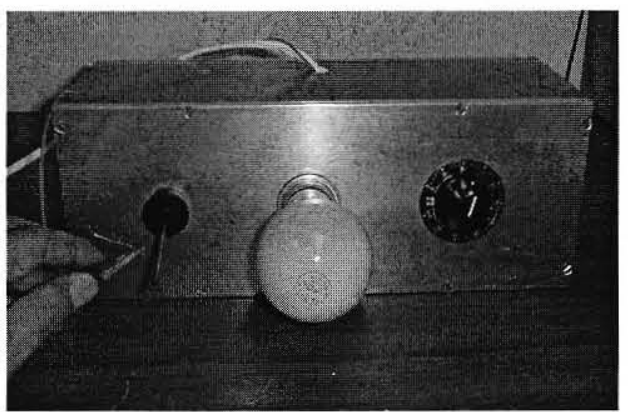

Figure 20. Thermocouple assembler G 
A thermocouple is a device primarily used for the measurement of temperature. It is based upon the findings of Seebeck (1822). His work showed that a small electric current will flow in a closed circuit composed of two dissimilar conductors when their junctions are kept at different temperatures. The electromotive force $(\mathrm{emf})$ produced under these conditions is known as the Seebeck emf. The pair of conductors, or thermoelements, that constitute the thermoelectric circuit is called a thermocouple. Simply stated, a thermocouple is a device, which converts thermal energy to electrical energy. The amount of electrical energy produced can be used to measure temperature [25]. In addition, the thermocouples are called thermoelectric contact sensors. A thermocouple is a passive sensor. It generates voltage in response to temperature and does not require any external excitation power. The (thermocouple) thermoelectric sensor belongs to the class of the relative voltage-generating sensors because the voltage produced depends on a temperature difference between two thermocouple junctions [14].

A Thermocouple assembly can be bare thermocouple twisted and welded, thermocouple wires on a plastic tubular carrier, insulated thermocouple twisted and welded, butt-welded thermocouple with fish- spine insulator, bare butt-welded thermocouple [14]. In the experiment, insulated wires were used to begin to make the thermocouples. The two ends of the thermocouple wire were attached to a conducting clip and instantaneously touched to a $\mathrm{Cu}$ plate by closing the circuit so that it made a spark and the tips of the metals melted and welded in one point producing the thermocouple joint. Then the welded thermocouple is made into a bare butt-welded thermocouple by removing the insulator. This bare butt-welded thermocouple is the best 
to use since it does not use extra soldering metal, which can affect the thermocouple function.

Table A. Characteristics of Thermocouple Types

\begin{tabular}{|c|c|c|c|c|}
\hline Junction Materials & $\begin{array}{l}\text { Sensitivity } \\
\left(\text { at } 25^{\circ} \mathrm{C}\right) \\
\left(\mathrm{uV} /{ }^{\circ} \mathrm{C}\right)\end{array}$ & $\begin{array}{l}\text { Temperature } \\
\text { Range }\left({ }^{\circ} \mathrm{C}\right)\end{array}$ & Applications & Designation \\
\hline Copper/constantan & 40.9 & -270 to 600 & $\begin{array}{l}\text { Oxidation, reduction, } \\
\text { inert,vacuum; preferred } \\
\text { below } 0^{\circ} \mathrm{C} \text {; } \\
\text { Moisture resistant }\end{array}$ & $T$ \\
\hline Iron/constantan & 51.7 & -270 to 1000 & $\begin{array}{l}\text { Reducing and inert } \\
\text { atmosphere: avoid } \\
\text { oxidation and moisture }\end{array}$ & $J$ \\
\hline Chromel/alumel & 40.6 & -270 to 1300 & $\begin{array}{l}\text { Oxidation and inert } \\
\text { atmospheres }\end{array}$ & $\mathrm{K}$ \\
\hline $\begin{array}{l}\text { Chromel/constanta } \\
\text { n }\end{array}$ & 60.9 & -200 to 1000 & & $\begin{array}{l}\mathrm{E} \\
\mathrm{S}\end{array}$ \\
\hline $\mathrm{Pt}(10 \%) \mathrm{Rh}-\mathrm{Pt}$ & 6.0 & 0 to 1550 & $\begin{array}{l}\text { Oxidation and inert } \\
\text { atmospheres; avoid } \\
\text { reducing atmosphere and } \\
\text { metallic vapors }\end{array}$ & \\
\hline $\mathrm{Pt}(13 \%) / \mathrm{Rh}-\mathrm{Pt}$ & 6.0 & 0 to 1600 & $\begin{array}{l}\text { Oxidation and inert } \\
\text { atmospheres; avoid } \\
\text { reducing atmosphere and } \\
\text { metallic vapors }\end{array}$ & $\mathrm{R}$ \\
\hline $\begin{array}{l}\text { Slver-Paladium } \\
\text { Constantan- } \\
\text { tungsten }\end{array}$ & $\begin{array}{l}10.0 \\
42.1\end{array}$ & $\begin{array}{l}200 \text { to } 600 \\
0 \text { to } 800\end{array}$ & & \\
\hline Silicon-aluminum & 446 & -40 to 150 & $\begin{array}{l}\text { Used in thermopiles and } \\
\text { micromachined sensors }\end{array}$ & \\
\hline
\end{tabular}




\section{The analog subtraction circuit}

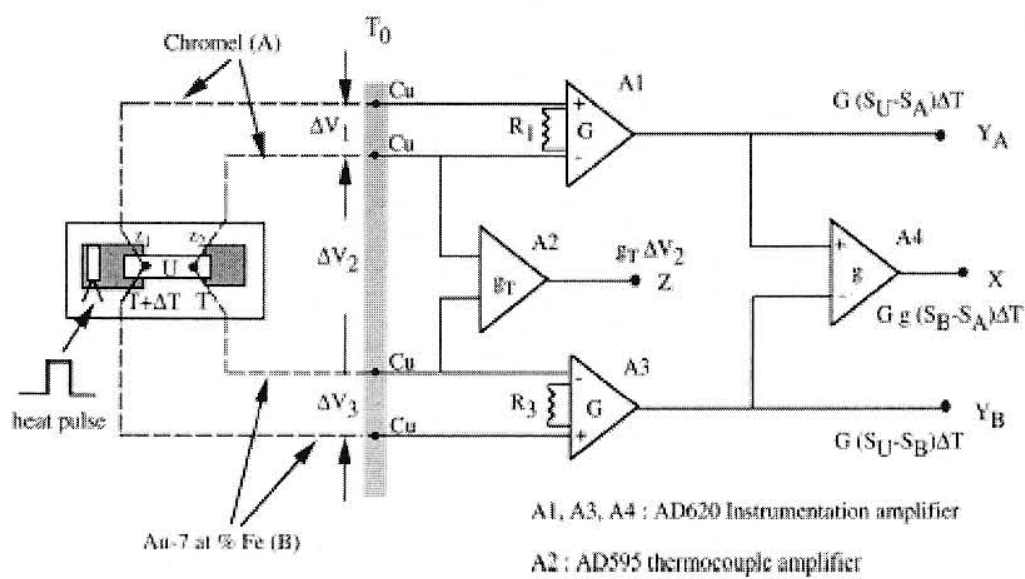

Figure 21: Analog subtraction circuit diagram [30,24]

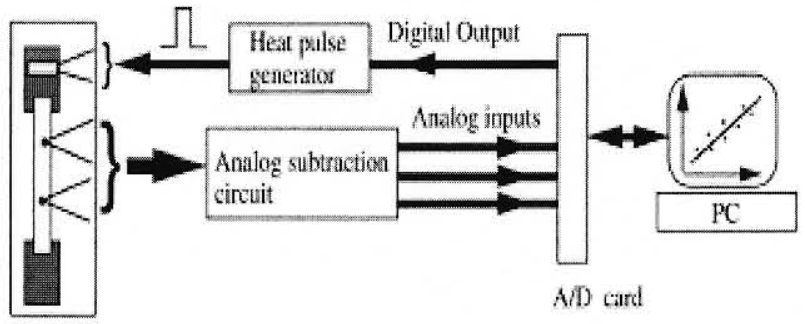

Figure 22 : Block diagram of thermopower measurement system [30,24]

The analog subtraction circuit was formed by three Analog Devices, Inc, AD620 instrumentation amplifiers A1, A3 and A4 as shown in the Figure 21. Amplifiers A1 and A3 were made to have gains $\mathrm{G}$ of 1000 . The variable resistors $\mathrm{R} 1$ and $\mathrm{R} 3$ were used to match their gains precisely. Amplifier A4 was constructed to have a gain g of 10 . The average sample temperature was measured by voltage $\Delta \mathrm{V} 2$ from the output of the $\mathrm{A} 2$ amplifier with a gain gT $[30,24]$. 


\section{E. The heat pulse generator}

The heat pulse generator was formed by a PIC 16C56 micro controller (Microchip Technology, Inc). This generator allows producing voltage pulses with variable height and width. It can be triggered by an external signal, which is sent by PC. The voltage pulse height and duration are adjustable in the ranges of $0-10 \mathrm{~V}$ and $1-20 \mathrm{~s}$, respectively. Depending upon the mass of the sample and heater, a temperature gradient of about $0.5 \mathrm{~K}$ was typically developed over the sample and relaxed over an interval about 5-20s $[30,24]$.

\section{F. The thermopower Reactor}

The thermopower reactor and the probe were modified from the previews experiments. The overall reactor length is $\sim 60 \mathrm{~cm}$ that is composed with a quartz reactor of $20 \mathrm{~mm}$ inner diameter and $\sim 25 \mathrm{~cm}$ in length equipped with a $2 \frac{3 / 4}{\mathrm{in}}$. knife-edge flange sealed via a $\mathrm{Cu}$ gasket to a standard multipin feed through flange. The sample holder with the sample attached to the electrical leads was placed at $\sim 9 \mathrm{~cm}$ from the end of the quartz reactor as show in the Figure24. The holder was composed of two Chromel-Alumel thermocouples, two additional $\mathrm{Cu}$ leads, a heater support and resistance heater as shown in the Figure 25. In addition, the probe consists of a header with a hermetic multipin connector for electrical input/ output and a vacuum valve. The thermocouples and the two $\mathrm{Cu}$ leads were attached with small amounts of silver epoxy to four corners of the $4 \mathrm{~mm} \mathrm{x}$ $4 \mathrm{~mm}$ sample to measure the TEP. The DC four-probe holder with the sample attached to the electrical leads was loaded into the glass reactor together with a small break-seal ampoule containing potassium. This model probe was necessary to release the alkali metal from the break-seal ampoule and maintain a temperature difference between the 
sample and the break-seal ampoule. Furthermore, the probe could be use to measure the carbon nanotubes sensitivity to any gas or toxic substances which may have potential applications in the National Defense.

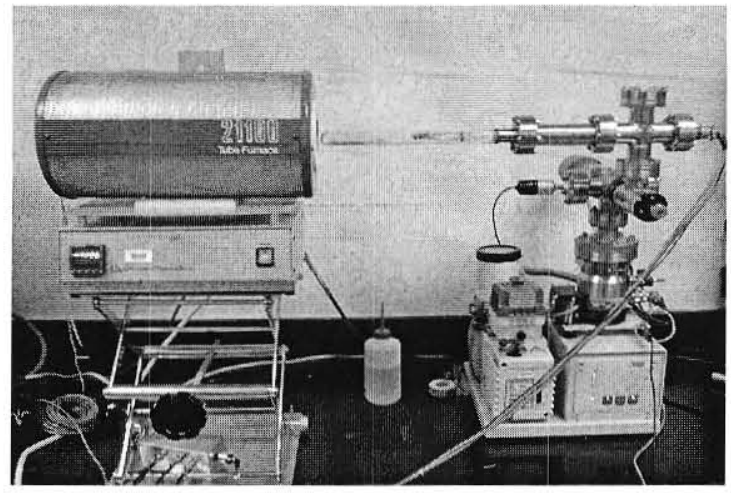

Figure 23. Thermopower reactor and probe

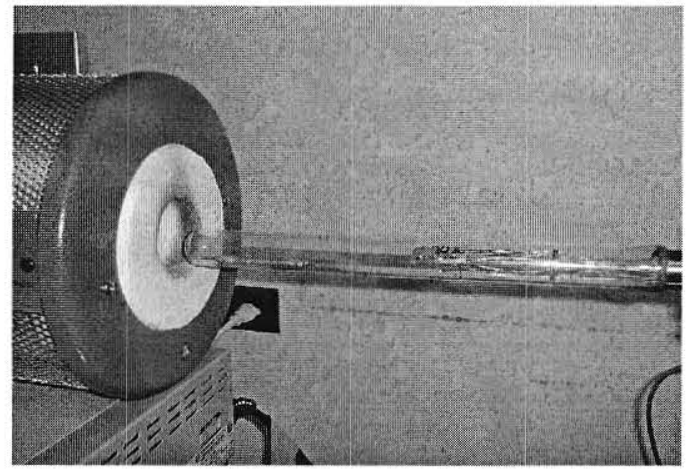

Figure 24. Reactor containing potassium ampoule and sample connected to a turbo molecular pump with the provision for heating inside a tube furnace

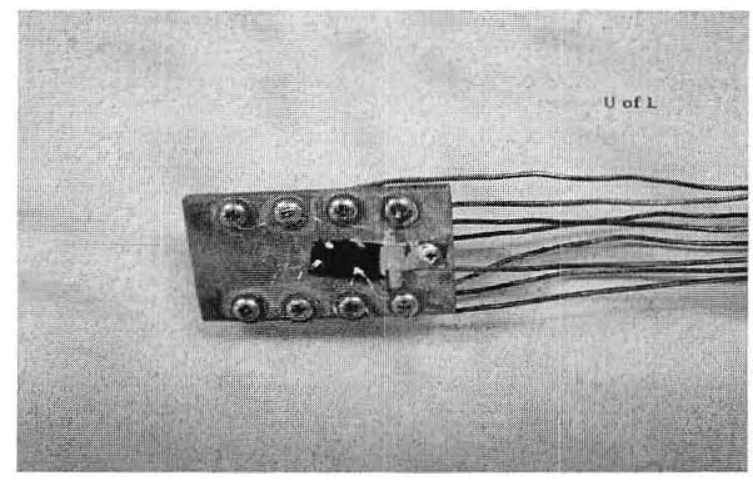

Figure 25. Holder 


\section{CHAPTER III}

\section{RESULTS AND DISCUSSION}

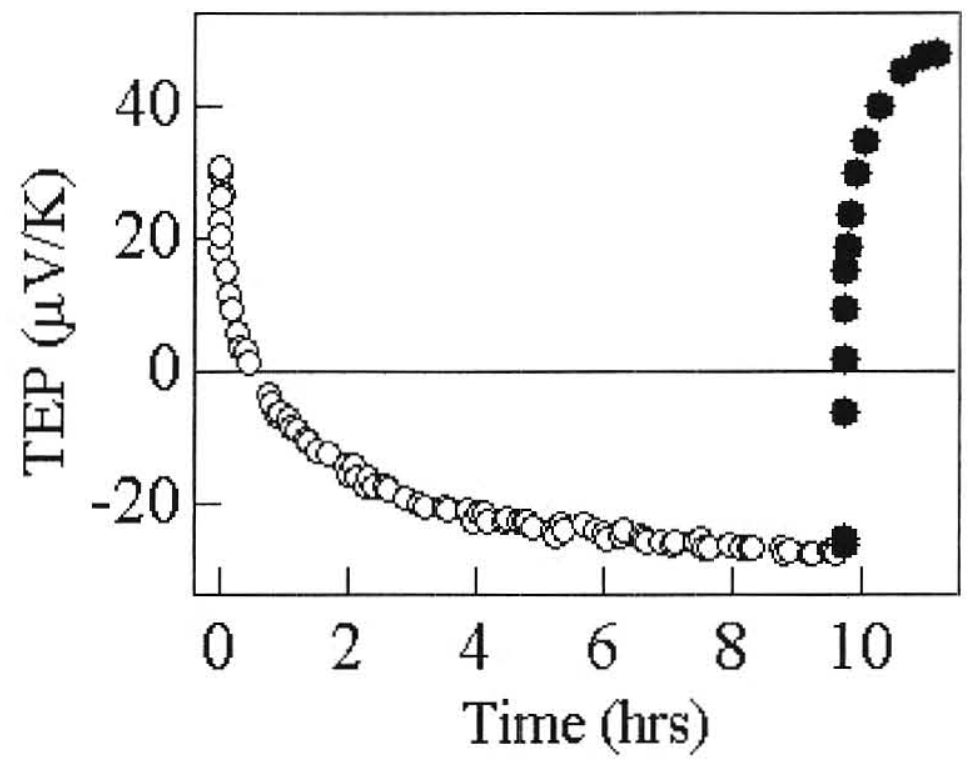

Figure 26. Thermopower response to vacuum and $\mathrm{O} 2(1 \mathrm{~atm})$ at $\mathrm{T}=500 \mathrm{~K}$. Vacuum degassing of a sample initially $\mathrm{O} 2$ doped under ambient conditions and exposure of the degassed sample to $1 \mathrm{~atm}$ of $\mathrm{O} 2$. Subsequent vacuum degassing has no effect on $\mathrm{S}$.

Figure (26) shows the time evolution of TEP at $\mathrm{T}=500 \mathrm{~K}$ for a typical purified thin film sample under vacuum. As the sample is degassed at $\mathrm{T}=500 \mathrm{~K}$ in vacuum $\left(<10^{-6} \mathrm{Torr}\right)$ the TEP was observed to decrease slowly from an initial value of a positive TEP, change sign and gradually approached a saturated value of a negative TEP (fully degassed) $[34,35,27]$. And when the fully degassed sample was exposed to 1 atm of pure $\mathrm{O}_{2}$ at 
$\mathrm{T}=500 \mathrm{~K}$ it has been found that the TEP irreversibly changed to a large positive value $[34,35,27]$.

Figure (27) shows a typical in situ variation of the resistance R normalized to the resistance of pristine SWNT mat Ro, with exposure time to K vapor. An initial drop in R was observed when the alkali-metal temperature reached $400 \mathrm{~K}$. Further sharp drops in R indicated with arrows in Figure (27) were observed when the furnace temperature was stepped up by $10{ }^{\circ} \mathrm{C}$. We have increased the furnace temperature in steps in order to be able to observe the diffusion kinetics.

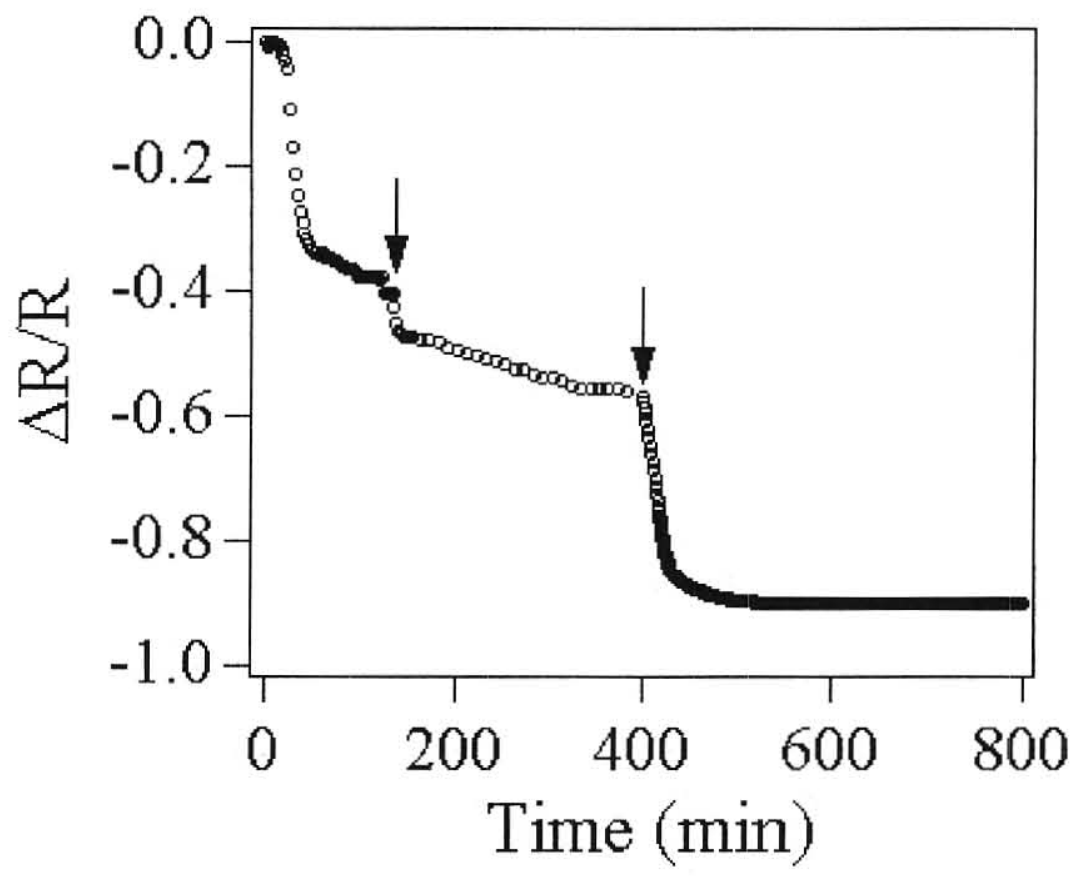

Figure(27) A typical in situ variation of four-probe dc resistance R of K-doped SWNT mats normalize to the $\mathrm{T}=400 \mathrm{~K}$ resistance of the pristine SWNT mat as a function of exposure time to $\mathrm{K}$ vapor.

The thermopower $(\mathrm{S})$ of each air-exposed sample shows strong p-type behavior consistent with previous studies. Interestingly, in contrast to previous studies on SWNT materials, this p-type behavior of S remained essentially unchanged during degassing at 
$500 \mathrm{~K}$ in vacuum $\left(<10^{-7}\right.$ Torr). It has been shown previously [33] that the p-type behavior observed in air exposed SWNTs could be easily driven n-type by in-situ degassing under these conditions. Further, it has been shown that if the degassed SWNTs are exposed to oxygen at temperatures above $500 \mathrm{~K}$, the thermopower is irreversibly changed to p-type, presumably due to strongly bound oxygen resulting in a C-O bond. It should be noted that the SWNTs used in this study are heated in dry air at $420^{\circ} \mathrm{C}$. For the peapod sample, the irreversible p-type behavior could be due to the same reason. A second possible explanation is that a small charge transfer between C60 and SWNTs can result in pinning the Fermi energy near the valance band-edge independent of oxygen adsorption / desorption. Another possibility is that the endohedral C60 blocks the oxygen molecules from desorbing out of peapods. The third scenario is more likely in explaining the irreversibility of p-type behavior in DWNTs. The annealing of peapod sample at 1200 ${ }^{\circ} \mathrm{C}$ in a vacuum $<10^{-7}$ Torr should be sufficient to remove all the oxygen adsorbed on the carbon surfaces. Any oxygen blocked by C60 could be trapped during the coalescence of the $\mathrm{C} 60$ molecules during the annealing.

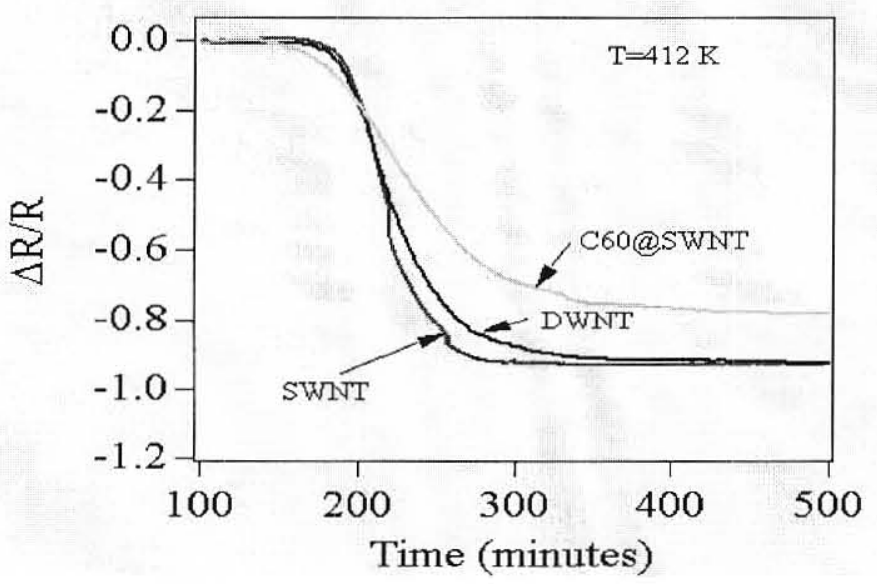

Figure ( 28 ). In situ variation of four-probe resistance R of K-doped SWNT, peapods, and DWNT mats normalized to the $\mathrm{T}=412 \mathrm{~K}$ resistance (before the doping started) as a function of exposure time to $\mathrm{K}$ vapor. 


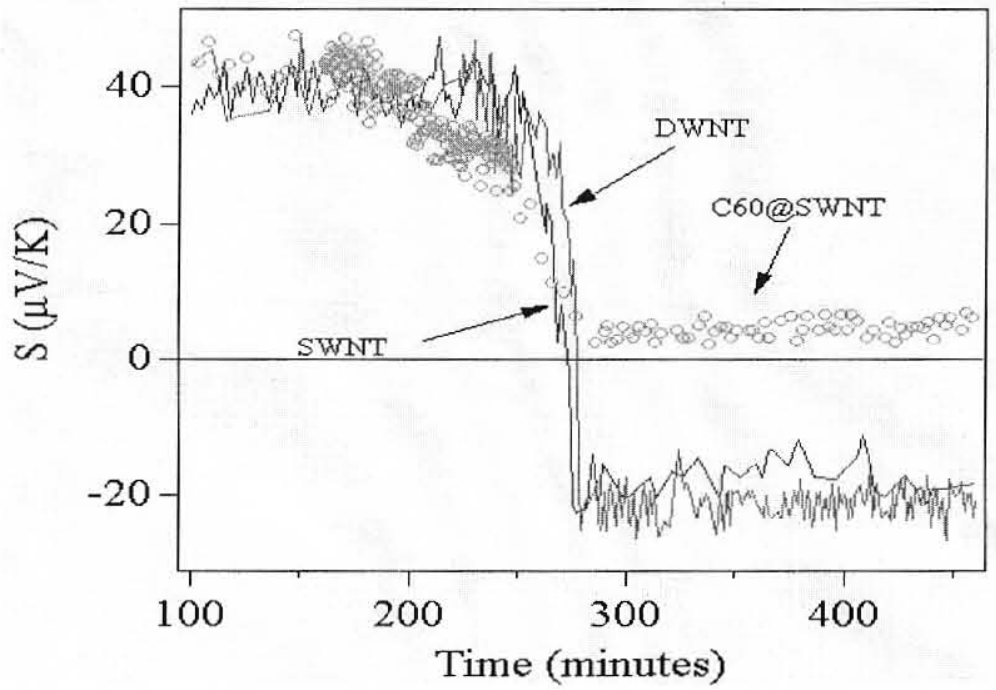

Figure ( 29 ) In situ variation Thermopower S of K-doped SWNT, peapods, and DWNT mats as a function of exposure time to $\mathrm{K}$ vapor.

Figure (28) shows the K-doping effects of the resistance (normalized to the resistance of the undoped sample at $\mathrm{T}=412 \mathrm{~K}$ ) of the three samples, SWNT, peapods, and DWNT. They all show a drastic drop of resistance of $\sim 80-95 \%$. Interestingly SWNT and DWNT show almost the same change in resistance, while the change for peapod is somewhat less. Figure (29) shows the concomitant result of the thermopower for the three samples during the K-doping. Again, SWNT and DWNT show very similar changes in TEP; starting $\sim 40 \mu \mathrm{V} / \mathrm{K}$, decreasing in magnitude, reversing the sign and eventually saturating at $\sim-20 \mu \mathrm{V} / \mathrm{K}$. Most interestingly, the TEP of the peapod sample saturates at only $\sim 0$ $\mu \mathrm{V} / \mathrm{K}$ without reversing the sign.

Doping effects on both resistance and TEP suggest that the charge transfer properties between K and SWNT or DWNT are very similar consistent with the observation on charge transfer properties on Raman spectra of SWNTs and DWNTs. But peapods show entirely different behavior as can be expected due to the mediation of $\mathrm{C} 60$ during the charge transfer process or possibly due to KC60@SWNT metal behavior. Raman studies 
on charge transfer in peapods have revealed competition between $\mathrm{C} 60$ and SWNTs during the charge transfer process. This behavior is not well understood and is currently under theoretical investigation. A likely scenario is that the Fermi energy is pinned near the midpoint between the valence band and the conduction band due to the presence of $\mathrm{C} 60$.
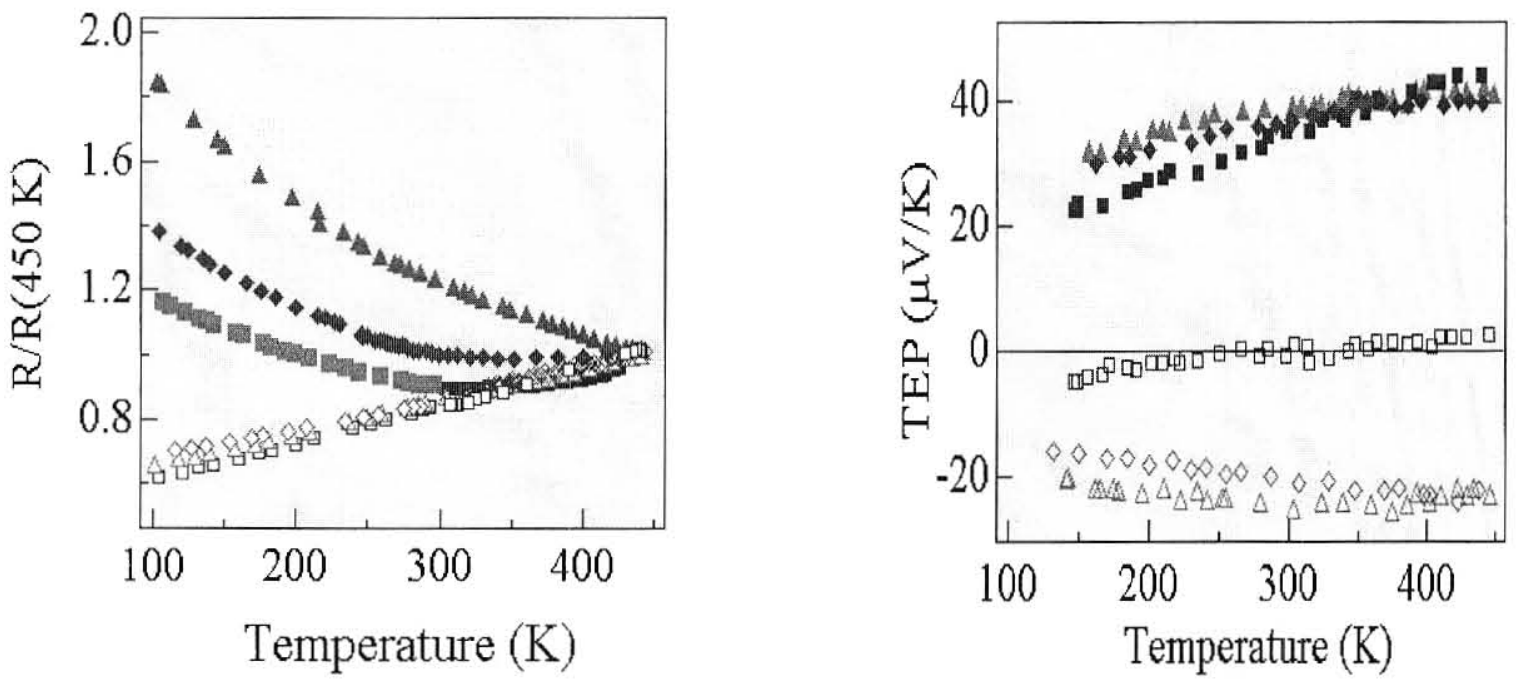

Figure 30. Temperature dependence of (a) Resistance R (b) TEP S before and after saturation doping with $\mathrm{K}$ for SWNTs,peapods, and DWNT mats.

Figure (30) shows the temperature dependence of the resistance and the TEP of the three samples before and after K-doping. Unfortunately, the low temperature data is for $\mathrm{T}>100 \mathrm{~K}$ for obvious technical reasons. It is clearly seen that all three samples show typical temperature dependence of resistance and TEP characteristic of SWNTs before doping. After doping, they show obvious metallic behavior. 


\section{CONCLUSIONS:}

In situ study of K-doping in SWNTs, C60@SWNTs, and DWNTs was done by monitoring resistance and thermopower. The data suggest that the charge transfer effects are similar in SWNTs and DWNTs, but drastically different in C60@SWNTs. All three samples show p-type behavior before doping presumably due to oxygen doping. Degassing at $500 \mathrm{~K}$ under high vacuum is not sufficient to desorb oxygen suggesting a stronger $\mathrm{C}-\mathrm{O}$ bond.

Doping effects on both resistance and TEP suggest that the charge transfer properties between K and SWNT or DWNT are very similar consistent with the observations on charge transfer properties on Raman spectra of SWNTs and DWNTs. But peapods show entirely different behavior as can be expected due to the mediation of C60 during the charge transfer process. Raman studies on charge transfer in peapods have revealed competition between $\mathrm{C} 60$ and SWNTs during the charge transfer process. It has been by Raman spectroscopy studies that for high levels of potassium doping in peapods in addition to the charge transfer to the SWNT's pods the C60 peas are charged up to $\mathrm{C}_{60}{ }^{-6}$ and forma metallic one-dimensional polymer. Now the parallel network of Kdoped SWNT pods and metallic 1-D polymer can result in thermpower $\sim 0 \mathrm{mV} / \mathrm{K}$ as been observed. For two conducting channels with si and $\mathrm{Si}(\mathrm{i}=1,2)$, the effective thermopower $\mathrm{S}$ can be written as, $\mathrm{S}=(\mathrm{s} 1 \mathrm{~S} 1+\mathrm{s} 2 \mathrm{~S} 2) /(\mathrm{s} 1+\mathrm{s} 2)$. This behavior is not very well understood and currently under theoretical investigation. A likely scenario is that the Fermi energy is pinned near the midpoint between the valence band and the conduction band due to the presence of $\mathrm{C} 60$. 


\section{REFERENCES}

1. Adu, C. K. W., Sumanasekera, G. U., Pradhan, B. K., Romero, H. E., Eklund, P.

C. “Carbon nanotubes: A thermoelectric nano-nose." Chemical Physics Letters 337 (2001) 31-35.

2. Andreoni, W. The Chemical Physics of Fullerenes 10 (and 5) Years Later: The Farreaching Impact of the Discovery of C60. Netherlands: Kluwer Academic Publisher. (1996)

3. Bandow, S., Takizawa, M., Hirahara, K., Yudasaka, M., Iijima, S. "Raman scattering study of double-wall carbon nanotubes derived from the chains of fullerenes in single-wall carbon nanotubes." Chemical Physics Letters. 337 (2001) $48-54$

4. Birkett, P.R. "Fullerenes." Annu. Pep. Prog. Chem., Sect. A, (2002) 98, 455-477

5. Chen, G., Bandow, S., Margine, E.R., Nisoli, C., Kolmogorov, A. n., Crespi, V. H., Gupta, R., Sumanasekera, G.U., Iijima, S., and Eklund, P.C." Chemical Doped Double-Walled Carbon Nanotubes: Cylindrical Molecular Capacitors.” Physical Review Letters, Vol. 90, Number 25 (2003)

6. Ci, L., Zhou, Z., Tang, D., Yan, X., Liang, Y., Liu, D., Yuan, H., Zhou, W., Wang, G. and Xie, S. "Double Wall Carbon Nanotubes with an Inner Diameter of $0.4 \mathrm{~nm}$." Chemical Vapor Deposition. (2003) 9, No. 3 
7. Claye, A., Rahman, S., Fischer, J.E., Sirenko, A., Sumanasekera, G.U., Eklund, P.C. "In situ Raman scattering studies of alkali-doped single wall carbon nanotubes." Chemical Physics Letters. 333 (2001) 16-22.

8. Cumings, J., Mickelson, W., Zett, A. "Simplified synthesis of double-wall carbon nanotubes." Solid state communications. 126 (2003) 359-362

9. Daenen, M., de Fouw, R. D., Hamers, B., Janssen, P.G.A., Schouteden, K., Veld, M. A. (2003, February). Wondrous World of Carbon Nanotubes "a review on current carbon nanotube technologies." Retrieved from http://students.chem.tue.nl/ifp03/default.htm

10. Dresselhaus, M. S., Dresselhaus, G. and Ph. Avouris, Carbon nanotubes: Synthesis, Structure, Properties and Applications

11. Dresselhaus, M.S., Dresselhaus, G., Eklund, P. C., Science of Fullerenes and Carbon nanotubes, (academic Press, San Diego, CA, 1996)

12. Ebbesen, T. W. (1997) Carbon Nanotubes preparation and Properties New Jersey: Nec Research Institute Princeton.

13. Ehrenreich, H., Spaepen, F. Solid State Physics, ( Academic Press, Inc. 1994 )

14. Fraden, J., Handbook of Modern Sensors: Physics, Designs, and Applications, Third Edition (Springer-Verlag, Inc. 2004)

15. Harris, Peter J. F. Carbon Nanotubes and Related Structures New Materials for the Twenty-first Century, ( Cambridge University Press, 1999)

16. Iijima, S. “Carbon Nanotube.” NEC Laboratories. 1994-2004 http://www. labs.nec.co.jp/Eng/innovative/E1/myself.html

17. J.Vavro, M., Llaguno, C., Satishkumar, B.C., Haggenmueller, R., Winey, K.I., Luzzi, D.E., Fischer, J.E., Sumanasekera, G.U., Eklund, P.C. “Electrical and Thermal 
Properties of C60-filled single Wall Carbon Nanotubes.” American Institute of Physics. (2002)

18. Jalilian, R. (2004). Novel synthesis techniques for nanostructures. Unpublished thesis, University of Louisville at Louisville.

19. Jiang, Q., Qu, M.Z., Zhou, G.M., Zhang, B.L., Yu, Z.L. “A study of activated carbon nanotubes as electrochemical super capacitor electrode materials." Materials Letters 57 (2002) 988-991

20. Jinno, K. Separation of Fullerenes by Liquid Chromatography, ( The Royal Society of Chemistry, Cambridge, UK, 1999 )

21. Jishi, R. A., Inomata, D., Nakao, K., Dresselhaus, M.S., and Dresselhaus, G. “ Electronic and Lattice Properties of Carbon Nanotubes." Journal of the Physical Society of Japan. Vol. 63, No. 6 (June, 1994)

22. Kavan, L., Kalbac, M., Zukalova, M., Krause, M. and Dunsch, L. “Electroquimical Doping of Double Walled Carbon Nanotubes: An In Situ Raman Spectroelectrochemical Study." ChemPhysChem, 5 (2004) 274-277

23. Meunier, V., Kephart, J., Roland, C., and Bernholc, J. " Ab Initio Investigations of Lithium Diffusion in Carbon Nanotube Systems." Physical Review Letters. Vol. 88, No. 7 (2002)

24. Patel, U. M. (2003). The effects of gas adsorption/Desorption on thermopower of mats of entangled bundles of SWNTs at Higher temperatures. Unpublished thesis, University of Louisville at Louisville.

25. Pollock, D. D. Thermoelectricity: Theory Thermometry Tool, ( ASTM Special Technical Publication 852, Philadelphia, PA, 1985 ) 
26. Porter, C., Taberna, P.L., Simon, P., Laberty-Robert C. "Modification of Al current collector surface by sol-gel deposit for carbon-carbon supercapacitor applications." Electrochimica Acta 49 (2004) 905-912.

27. Romero, H. E., Sumanasekera, G.U., Mahan, G.D., and Eklund, P.C.

"Thermoelectric power of single-walled carbon nanotubes films." Physical Review B, Volume 65, $205410(2002)$

28. Saito, R., Dresselhaus, G., Dresselhaus, M.S., Physical Properties of Carbon Nanotubes, (Imperial College Press, 1998)

29. Schneuwly, A. Gallay, R. "Properties and applications of supercapacitors Fron the state-of-the-art to future trends" Proceeding PCIM (2000).

30. Sumanasekera, G. U., Grigorian, L., and EKlund, P. C. "Low-temperature thermoelectrical power measurements using analogue subtraction." $\underline{\text { Meas.Sci }}$ Technol. 11(2000) 273-277.

31. Sumanasekera, G.U., Adu, C. K. W., Fang, S., and Eklund, P.C. "Effects of Gas Adsorption and Collision on Electrical Transport in Single-Walled Carbon Nanotubes.” Physical Review Letters. Volume 85, 5 ( 31 July 2000)

32. Sumanasekera, G.U., Adu, C. K. W., Pradhan, B. K., Chen, G., Romero, H. E., and Eklund, P. C. " Thermoelectric study of hydrogen storage in carbon nanotubes." Physical Review B, Vol. 65, (2001) 035408

33. Sumanasekera, G.U., Adu, C.K.W., Fang, S., and Eklund, P.C. “Effects of Gas Adsorption and Collisions on Electrical Transport in Single-Walled Carbon Nanotubes." Phys. Rev. Letters, 85, 5 ( July 2000) 
34. Sumanasekera, G.U., Pradhan, B. K., Adu, C.K.W., Romero, H.E., Foley, H. c., and Eklund, P.C." Thermoelectric Chemical Sensor Based on Single Wall Carbon Nanotubes.” Mol. Cryst. Liq. Cryst., Vol. 387, (2002) pp. [255]/31-[261]/37

35. Sumanasekera, G.U., Pradhan, B.K., Romero, H.E., Adu, K.W., Eklund, P.C. "Giant Thermopower Effects from Molecular Physisortion on Carbon Nanotubes." Physical Review Letters. Volume 89, number 16 ( October, 14 2002)

36. Wang, Zhong L., Liu, Y., and Zhang, Ze. Handbook of Nanophase and Nanostructured Materials: Volume 1,2,3,4 ( Kluwer Academic / Plenum Publishers, Tsinghua University Press, 2003 )

37. Wei, J., Jiang, B., Zhang, X., Zhu, H., Wu, D. “ Raman study on double-walled carbon nanotubes." Chemical Physics Letters, 376 (2003) 753-757

38. Wei, J., Jiang, B., Wu, D., and Wei, B. " Large-Scale Synthesis of Long DoubleWalled Carbon Nanotubes." J.Phys. Chem. B Vol. 108, No. 26, （2004 )

39. Yang, C., Wohlenannt, M., Vardeny, Z. V., Blau, W.J., Dalton, A. B., Baughman, R., Zakhidov, A.A. " Photoinduced charge transfer in poly (p-phenylene vinylene) derivatives and carbon nanotube/ C60 composites.” Physica B, 338 (2003) 366-369.

40. Yoshimura, S., Chang, R.P.H. (Eds.), Supercarbon Synthesis, Properties and Applications. ( Springer-Verlag Berlin Heidelberg, 1998) 


\section{CURRICULUM VITAE}

NAME: Jose Ernesto Rivera

ADDRESS: Department of Physics

102 Natural Sciences Building

University of Louisville

Louisville, KY 40292.

DOB: $\quad$ Cayambe, Ecuador - July 14, 1961

EDUCATION

\& TRAINING: $\quad$ B.S, Physics

University of Louisville

$1994-2002$

M.S, Physics

University of Louisville

Louisville, KY 40292

2002-2004

PROFESSIONAL SOCITIES:

Member of National Society of Physics Students

Golden Key National Honor Society 